\title{
Neues zum Buche der kamonianischen, Lieder und Briefe.
}

Je länger und inniger ich mit dem herrlichen Buche der verdeutschten kamonianischen Lieder verkehre, um so mehr lerne ich die Kunst des Übersetzers und seine unvergleichliche Sorgfalt bewundern. Hie und da entfernt sich aber meine Deutung schwieriger und dunkler Stellen, an denen die Redondilhas reicher sind, als man von vorn herein vermutet, doch von der Deutung Storcks. Hic und da befriedigt mich auch die Übersetzung als solche nicht ganz. Besonders ist für die schlichte Einfalt und Schmucklosigkeit einiger kurzzeiliger Schelmenliedchen der Harnisch deutschen Ticfsinnes zu schwer und allzu wuchtig; und der zu grofse Reichtum deutschen Gefühles, mit dem der Übersetzer jene ausgestattet hat, überbürdet sie und raubt ihnen ihre leichte Anmut und ihr volkstümliches Gepräge. Zu viel Kunst! zu viel Schmuck! zu grofser Reichtum! zu grofse Gründlichkeit! möchte ich manchmal sagen. Über alle diese Fälle nun, in denen, nach meinem Geschmack und meinem Verständnis, etwas anders sein mürste als es ist, möchte ich gar gern mit meinem Freunde plaudern. Da das leider aber mündlich nicht sein kann, weil Münster und Porto allzuweit auscinander liegen, so geschehe es schriftlich: mancherlei, was ich zusammen gelesen und was einem so gründlichen und enthusiastischen Camoenskenner, wie Storck es ist, nicht verächtlich und kleinlich erscheinen wird, hoffe ich ihm dabei erzählen zu können. Vielleicht findet sich unter diesen Stoppeln, die ich so vom Erntcfelde meines Freundes gesammelt, hie und da auch eine wirklich brauchbare Weizenähre.

Zu No. I I -5. Die erste Strophe des wahrhaft beliebten Gesanges ward im 17. Jahrh. von Antonio Barboza Bacelar glossiert in 5 Decimen (s. Feniz Renascida I p. 185). Ich führe diese und ähnliche Erscheinungen absichtlich sorgsam an, da sie deutlich und klar machen, welche von den lyrischen Gedichten des Lusiadensängers wirklich Allgemeingut der Nation geworden und jedem Gebildeten bekannt waren.

$\mathrm{Zu}$ No. II. Zum dreihundertjährigen Todestage des Dichters veröffentlichte A. F. Barata in einem von mir bereits (Ztschr. IV 594 Anm. I) erwähnten Festschriftchen, nach Manuskripten der Bibliothek von Evora, einige sogenannte Inedita de Camies: zwei Sonette und eine Redondilha. Letztere ist, gerade so wie das von Storck 
unter No. 2 übersetzte Gedicht, betitelt: "Ao desconcerto do mundo". Der Herausgeber bekennt ausdrücklich, dafs die beiden Handschriften, welche die Strophen enthalten ( $\frac{\text { exiv }}{2-2}$ fol. 184 und $\frac{\text { CXx } 1}{2-25}$ Schlu(sblatt), den Namen des Verfassers gar nicht angeben: sie Camoens zuzuschreiben habe ihn nichts anderes als die (gedruckte) diesbezügliche Aussage des Oberbibliothekars Joaquim Antonio de Sousa Telles de Mattos bewegt. Selbiger bezeichnet sic nämlich im Handschriften-Katalog der Bíbliotheca Publica Evorense (Bd. II S. 91) als Poesias de Luiz de Camðes, wovon Jeder, der den Katalog besitzt, sich überzeugen kann. Nur steht daselbst kein Wörtlein darüber, ob besagte Trovas allbekannte oder unbekannte Werke des Dichters seien. Die Neuigkeit, sie seien Inedita, hat erst Herr Barata verbreitet, wie ich vermute darauf fufsend, dafs im Katalog die Verse einfach als kamonianisch rubriciert sind, während Herr Telles de Mattos bei Aufzählung anderer, Camocns zugeschriebener, schon gedruckter Werke, welche die Bibliothek gleichfalls besitzt, wie z. B. die Prosabriefe, die Bemerkung macht, "sie ständen gedruckt in seinen Werken" (p. 177). Doch, dem sei wie ihm sei, jedenfalls hat Herr Barata nicht bemerkt, dals die Verse

oder

„Sempre no mundo vi passar

aos bons graves tormentos

[Vi aos bons sempre passar

$\mathrm{Na}$ vida graves tormentos]

e pera mais me espantar

aos maos sempre vi nadar

em mares de contentamentos.

Cuidando alcansar eu assim

este bem desordenado,

fui mao, mas fui castigado,

de sorte que so pera mim

anda o mundo concertado".

bis auf einige ganz unbedeutende Varianten, genau dieselben sind, welche seit 1598, unter dem gleichen Titel, in allen CamoensAusgaben stehen; dieselben, welche Dom Francisco de Portugal schon in seinen Prisøes e Solturas de hüa alma (p. I3) citiert; dieselben, welche später Quevedo (Rivadeneyra Bd. 69 S. 94) in eine seiner berühmten Letrillas Satiricas, in

Fui bueno, no fui premiado

y viendo revuelto el polo

fui malo y fui castigado,

asi que para mi solo

algo el mundo es concertadv

eingeflochten hat; dieselben, welche auch Francisco de Mello in seinem Apol. Dial. I „Relogios Fallantes" p. 3 benutzt:

parece que só para mim

anda o mundo concertado; 
dieselben also, welche Storck unter No. 2 übersetzt. Da mufs man unwillkürlich wieder einmal, wie bei recht vielen Bemerkungen moderner Portugiesen über ihren Nationaldichter, leise vor sich hinsummen:

Wer wird nicht den Camoens loben?

Doch wird ihn jeder lesen? Nein! -

Wir wollen weniger erhoben

Und mehr gelesen sein!1

1 Ich benutze die Gelegenheit, um diejenigen, welche begierig darauf waren, die neu veröffentlichten Inedita Camoniana kennen zu lernen, ohne doch der kleinen Schrift von Barata habhaft werden zu können, darüber aufzuklären, dafs das eine der fraglichen Sonette nichts ist als eine Glosse zur ersten Zeile des 18. kamonianischen Sonettes, das auch Francisco Rodriguez Lobo umschrieben hat (Obras p. 192):

„Doces lembranças da passada gloria“.

Ein Kundiger hatte neben diese letzte Zeile das Wort "Camores" geschricben: einem weniger Kundigen war es vorbehalten, daraufhin das arme Scherflein des ganzen, unschönen Sonettes für den reichen Liebling der Nation in Anspruch zu nehmen. Der antikamonianische Geist des fraglichen gongoresken Machwerkes ist jedoch so auffälig, dafs auch Herr Barata Zweifel an der Echtheit seiner Altribution äufsert: das sei zur Ehre der Wahrheit bemerkt. Hier folgt es:

Aqui neste ás idades consagrado

campo fatal, adonde peregrinas

pagam ja natural censo as boninas

do barbaro cultor ao duro arado;

aqui neste d'abril throno abrasado, de edificio, composto de ruinas, reliquias doces, mas de magoa dinas; aqui foi Troya para meu cuidado.

Aqui venho chorar tanta mudança e, celebrando exequias a memoria, acabar de enterrar minha esperança;

- aqui dar d'estas pedras nova historia

e aqui deixar ao tempo por memoria (sic; ich vermute heranca) "doces lembranças da passada gloria".

Das zweite der fraglichen Sonette giebt sich in der Überschrift als ein Werk des Dichters kund. Ob mit Recht, kann ich nicht entscheiden. Es lautet

$$
\text { Soneto de luis de camois. }
$$

Vingo-me, em parte estando da ventura, com seu engano e minha confiança que cuida que com seu poder alcança tirar-me d'alma vossa fermosura.

(Que) pode mudar-me a vida aspera e dura, mas não de vós, meu bem, minha lembrança. Os olhos passão o mal e a mudança; a alma, onde vos estaes, está segura.

E vendo vossas graças sempre n'ella, meus sentidos, em vós sempre enlevados, estão tambem com ella em minha ajuda.

Venço a ventura; assi posso mais que ella, que em meu mal tem seus peis tam contiados que em mim, sendo mudavel, seu ser muda. 
Zu No. III. Als meisterhafter Nachahmer dieses kamonianischen Labyrinthes hat sich Francisco Alvares do Oriente gezeigt. In seiner "Lusitania transformada" findet sich (p. I 80) ein Labyrinth von 25 Quintillen; und cin weiteres von 8 Oktaven (p. 182). Eine gute Erklärung der metrischen Spielerei ist dem ersten Probestück beigegeben. Sie lautet: Vejo nestas letras outro laberinto fabricado por algum alto engenho, de que vos confesso que me nato sei sahir. Acho que cada cinco regras destas respondem humas a outras com tanta consonancia que por onde quer que as tomo fazem huma tao perfeita, que ndo só responde a todas as leis da poesia, mas ao proposito do sentido tao compridamente que me tem maravilhado o seu estranho artificio... E tomando cada hum as regras delle por varias partes, achava que cahido todas tao a proposito que nao puderino todos deivar de as engrandecer...

Zu No. VI. Auch ich glaube, dafs dies Gedichtchen mit dem Frauennamen Graça oder Gracia spielt, also an cine "Graça“ getaufte Schöne gerichtet ward. Der ganze Inhalt, besonders aber Zeile 10, scheint es zu bestätigen. Die Zahl der portugiesischen und spanischen Gedichte, welche mit bedeutungsvollen Namen wie „Paz, Luz, Estrella, Dolores“ etc. ein oft sinniges, oft unsinniges Spiel treiben, ist Legion. Camoens selbst "heult mit den Wölfen“ d. h. er folgt der Gesellschaftsmode mehr denn einmal: in Son. 209 feiert er eine Paz; eine Justa Paz in Son. 257; eine Gama in Red. 380; eine Justa vielleicht in Red. 49; einen Faria in Son. 193.

No. VII. Die Absichtlichkeit, mit der im portugiesischen Originale in jeder Zeile das Wort olhos = Augen angebracht ward, ist vom Übersetzer nicht beachtet worden. Ein Nachklang der alten Coblas capdenals dürfte darin gefunden werden.

No. VIII. Die Nachdichtung dieses „Fehdebriefchens eines Verschmähten" scheint mir weder richtig und treu, noch elegant und klar und verständlich. Der Übersetzer hatte mit einem mangelhaften Texte zu thun. Demselben fehlte die echte tonangebende Überschrift; eine vermutlich charakteristische Zeile war gestrichen; ein grober Fehler war, nebst vielen kleinen, stecken geblieben und zwar ein Fehler, der am vollen Verständnis hindert. Wer aber kann ohne absolutes Verständnis des Originals richtig, treu, elegant und klar übersetzen? Storck hat im Gefühl davon, dafs etwas in dem Gedichte mangelhaft sei, am portugiesischen Texte selbst mehrfach gebessert; - den sinnstörenden Fehler hat er nicht entdeckt, die Lücke meinør Meinung nach nicht glücklich ausgefüllt. Stellen wir zunächst des Dichters Wort und Absicht wieder her. Die charakteristische Adresse des Briefes, welche der Herausgeber Juromenha wohl absichtlich fortgelassen, lautet: Novas em resposta que um galante mandou a hüa dama, que ja tinha della o que queria, $e$ ella lhe mandou dizer que se esquecesse do passado. Responde e diz. Dieser kleinen Mitteilung entsprechend mülste das ganze Gedicht im Deutschen einen etwas keckeren, ja frechen Ton anschlagen. Das innige, wahre Gefühl, das Storck hineingelegt, spricht aus dem Originale nicht. Und die in der dritten Strophe fehlende Zeile 
(die vielleicht ein gewissenhafter Kopist aus Schicklichkeitsgefühl unterdrückte) müfste nicht von „Schmerz“, sondern von "genossener Iust“ sprechen. Auch Phrasen wie „das Wen'ge, was ich vordem nannte mein" (16-17), das ,in Ruhe mich bescheiden" (18) und das Pochen auf "Gram und Leiden“ sind viel zu poesievoll und zart. - Der schon erwähnte Hauptfehler aber steckt in der zweiten Strophe. In den portugiesischen Ausgaben, bei Juromenha und Braga, lautet dieselbe:

Bem que a razão vejo clara,

Que alguem vos enganou,

Porque eu certo julgava

Que o fio não quebrára

Pelo logar que cobrou.

In der Übersetzung heifst es:

Hört' ich doch, nicht mehr beflisse

Sich um Euch cin sichrer Mann,

(Der doch - meint' ich einst - gewisse

Fäden nicht so leicht zerisse)

Seit er höhren Rang gewann.

Die Parenthesen rühren von mir her: ich glaube durch dieselben den Sinn und die Meinung des Übersetzers leichter verständlich zu machen. Wie kam er zu dieser Auffassung und der etwas ungelenken Form? Die letzte Zeile des Originals - in welcher der Fehler steckt - mulste, eben um ihrer Unverständlichkeit willen, der Ausgangspunkt für die Übersetzung werden. Die im Alt- wie im Neuportugiesischen gleich unmögliche Formel "Cobrar um logar" ward aufgefarst, als hiefse sie „eine Stelle erhalten“ oder, wie der Dichter sich gewählter ausdrückt, "höhren Rang gewinnen". Wer aber crhielt die Stelle? Der "Jemand" mufste gesucht und konnte naturgemäls nur in dem alguem der zweitẹn Zeile entdeckt werden: daher die unnatürliche, nur gewaltsam herbeizuführende Zusammengehörigkeit von Zeile zwei und fünf; daher die notwendig daraus folgencle Isolierung von drei und vier, eine Isolierung, die der Übursctyer wieder alıhebt, indem er das betreffende Wortgefüge mit seinem einleitenden que als Relativsatz auffafst, dessen Subjekt abermals der unbekannte "Jemand“ und dessen Objekt der „zerrissene Faden" ist. Damit ist aber der ganze Inhalt verkehrt und verfälscht. - Statt cobrou lese man quebrou, wie der Sinn es fordert, und wie das einzige vorhandene Manuskript, welches das Briefchen aufbewahrt hat, wie also die Miscellanea Juromenha auch unverkennbar deutlich schreibt (cfr. Bd. IV p. 604 dieser Ztschr.). Folgender Gedankengehalt ergiebt sich dann naturgemäls: „Ihr, schöne Dame, wollt, dafs ich Euch nunmehr fern bleibe und Euer vergesse. So sagt mir doch gefälligst das Varum dieses Eures Willens; obzwar (so beginnt die zweite Strophe, um die es sich handelt) obzwar ich selbst den Grund Eures Wunsches klar einsehe, dars nämlich Jemand Euch 
betrogen hat (das kann so viel heifsen als: Jemand hat mich verleumdet, Euch Böses von mir erzählt, oder auch Jemand hat Euch durch scine Verführungskünste für sich crobert, jedenfalls aber bedeutet es, dafs ein Dritter an der Untreue der Dame schuld ist). Denn (man erwartet hier obschon, êm-l) statt porque), denn ich hielt es für gewifs, dafs der Faden (sc. unserer Verbindung) nicht reifsen könnte an der Stelle, bei der Gelegenheit, wo er in Wahrheit zerrissen: d. h. gerade am dicksten Ende, in dem Augenblicke, wo wir einander am innigsten nahe standen. Sagt doch das Sprichwort - das Volksevangelium, an das jeder gute Portugiese glaubt -: a corda sempre quebra pelo mais delgado.'

$\mathrm{Ob}$ das kecke Liedchen überhaupt von Camoens ist? Dic Quellenhandschrift besagt das keineswegs. Der einzige Umstand, der den Herausgeber veranlafst haben kann, es für kamonianisch zu erklären, ist der, dafs es in der Handschrift unmittelbar auf ein vermutlich dem Dichter zugehöriges Sonett folgt ("Tristezas", s. St. Il No. 357) und dafs nahebei einige andere unzweifelhaft von ihm herrührende Gedichte stehen. Ist er genügend? Mir scheint, man thue in jeder Hinsicht wohl daran, wenn man den „Absagebrief eines Verschmähten" unter die fälschlich und leichtfertig Camoens zugesprochenen, in Wahrheit aber vaterlosen Findlinge setzt.

Der vom Kopisten entstellte und vom Herausgeber nicht nur unverbessert gelassene, sondern noch anderweitig verderbte Text bedarf noch einiger kleiner Reformen, selbst nach den frei erdachten Besserungsversuchen Storcks, nach der oben erwähnten Berichtigung von Zeile 10, und nach weiteren auf Grund des Manuskripts vorzunehmenden Rektifikationen. Z. B. ist Zeile $24 N^{\prime}$ 'isso guanho eu mais eine unmögliche Redondilienzeile. Man lese Que n'isso ganho eu mais oder N'isso guaanho eu mais. In Zeile 17 ist natürlich statt Com o Co zu sprechen, und man thut besser, wenn man heutzutage auch also schreibt.

No. XI. Ob in der Überschrift, die ich schon früher (IV 604) mitgeteilt habe, nicht maldisposia statt maldisposto zu lesen ist? Der eigentlich Kranke und Mirsgelaunte ist ja doch die Dame, und nicht der Liebhaber. Dafs die vier Schlufszeilen (remate), welche die zweite, in Storcks Anmerkungen mitgeteilte Fassung des hübschen Schreibens an die kranke Freundin begleiten, nicht zu diesem gehören, sondern ein selbständiges Epigramm bilden, wie Storck meint, will mir durchaus nicht einleuchten. Dafs sie in der Handschrift thatsächlich mit dem Gedichte eng verbunden sind, entscheidet freilich nichts; entscheidend ist, in meinen Augen, nur dafs der Gedanke

Se a verdade dizer posso

Estar doente convinha

Vós não, que sois alma minha,

Eu sim, que sou corpo vosso.

1 Cfr. das kast. Sprichwort: quebrar la soga por lo mus delgado. 
unmittelbar, enge und untrennbar mit dem in den ersten vier Zeilen der vorhergehenden Strophe ausgesprochenen verknüpft ist, in welcher es heifst:

\author{
Que tanto mais qualquer dan.) \\ Vosso que o meu sentiria, \\ Quanto he maior a valia \\ D'alma que a do corpo humano.
}

(So und nicht que do steht im Ms.) Ja mir scheint das "Remate“ überhaupt das Facit des ganzen Briefchens zu sein, dem es vielleicht als Überschrift, vielleicht aber auch als Aufschrift beigegeben war.

Zum portugiesischen Texte bemerke ich noch einige Kleinigkeiten. Soll einmal die Regel durchgeführt werden, dafs Amor überall, wo er personificiert gedacht werden mufs, oder besser kann, d. h. dafs er überall da, wo das Wort ohne Artikel auftritt, mit grofsen Anfangsbuchstaben wie ein Figenname zu schreiben ist; so sind zu den zahlreichen von Storck gelegentlich herausgehobenen Stellen noch manche andere hinzuzufügen, wie z. B. in der zweiten Zeile dieses Gedichtes. Dabei sei noch erwähnt, dals, soll die andere Regel durchgeführt werden, dafs tonlose metrisch ungültige Vokale wirklich $z u$ elidieren sind, dals z. B. q'rer cap'lao off'recimento p'ra esp'rito und co für com $o$ überall da geschrieben werden mufs, wo also gesprochen wird, gleichfalls manches Beispiel zu den gesammelten nachzutragen ist; z. B. VIlI 17 Co. für com $o ; \mathrm{XIX}_{58}$ Cos für Com os etc.

No. XV 6-10. Mir scheint der Gedanke des Originals nicht treu, also nicht gut wiedergegeben zu sein. "Das alte tiefe Wehe, keine Fntschuldigung für sie zu finden, hat mir die Seele so vergrämt, dals ich sio schon für entschuldigt halten d. h. dafs ich ihr verzeihen werde, sobald sie nur ihre Schuld bekennen will". Wer hört diesen Gedanken aus den Worten heraus:

Weil ich nichts davon verstehe, (?)

Quält mich so mit Ungeduld

Mein erlitt'nes herbes Wehe,

Dafs Entschuld'gung schon ich sehe

Blofs im Eingestehn der Schuld.

Auch Zeile 24 ver que d'isso se contenta würde ich anders deuten als Storck, und verdollmetschen: „zu sehen, dafs sie sich dazu hergiebt, d. h. dafs sie darauf eingeht, dals es ihr recht ist, nämlich mir die Wahrheit zu gestehen"; und nicht wie Storck: „zu schen, dafs sie Freude daran hat, nämlich an meinen Peinen. Solch boshafter Zug palst nicht hierher. Zeile 56-65 würden, ein klein wenig anders gefalst, den Sinn noch genauer und verständlicher wiedergeben. Im Übrigen ist das Gedicht ganz herrlich übersetzt.

No. XVIII 16-20. Das im Portugiesischen bis zum Überdrufs abgenutzte Wortspiel zwischen pena Leid und penna Feder, das in 
dieser Strophe versteckter als gewöhnlich auftritt, ist deshalb wohl in der Nachdichtung unbeachtet geblieben. Amor gicbt Camoens eine Feder penna, damit er seine pena, sein Leid, damit niederschreibe. „Und da alles, was Amor verlangte, dafs ich schreiben sollte, mir Schmerzen machte, mir penas gal), so konnte ich von ihm sagen, dafs das, was er mir zum Schreiben gab (die penna), mir zu grlcicher Zeit zu schreiben gab (nämlich penas)“. - In Zeile 94 ist zu lesen Depois por manifestarme statt D. que m.

No. XIX. Die Handschrift, welcher Juromenha diesen Brief, gleichwie den nächstfolgenden (No. XX) entnahm, ist nicht die Miscellanea J; seine Quelle ist mir unbekannt. - Zeile 6: statt saudade em que ando (oder com que ando, wie Storck bessert) würde ich lesen saudddes com que ando, weil die Sehnsucht im Portugicsischen gewöhnlich in Pluralform auftritt. Das Wortspiel, das in saude und saudade liegt, konnte nicht berücksichtigt werden. 7. Man lese cem für sem. -8 . Storcks Umänderung von $E$ zu $E m$ ist keine notwendige. Annehmbar wäre sie überhaupt nur, wenn $\hat{e} m$ (= $a b$ inde) gemeint wäre, sodafs die einschlägige Phrase bedeutete: Hunderttausend Sehnsuchtsseufzer sende ich aus; darum doch nicht ohne solche zurückbleibend. 1 - 38. nao raros für tao raros scheint mir gleichfalls keine unerläfsliche Änderung. Der ironische Stil der familiären (doch ungleich feineren und schöneren Epistel, als es die folgende ist) lärst es sehr wohl zu, dafs der Dichter die lästigen Tage der Langeweile im Garnisonleben „so seltene“ nennt. - In Zeile I 26 (tao maltratar-me) steckt ein Fehler, doch weifs ich ihn nicht zu berichtigen. - 130. Man lese comigo? für commigo, - 150 neum für n'hum, - 157 assi für assim, 158 cos für com os.

Die geflügelten Worte, mit denen jede Strophe abschliefst, sind meistenteils stark verderbt, und Storcks Besserungsversuche haben trotz ihrer Vortrefflichkeit, natürlich da, wo sie ohne Erkenntnis und Kenntnis des Citates gemacht sind, nicht immer das Rechte treffen können. Im Nachstehenden verbessere ich stillschweigends den Wortlaut aller derjenigen, deren Quelle ich mit Sicherheit nachzuweisen im Stande bin. Leider sind es wenige an Zahl:

Zeile 15-16 entstammen einem Liedchen des 1514 in Afrika gefallenen Helden Dom João de Menezes.2 Dasselbe steht im Canc. gen. de 1557 auf fol. 18I; im Canc. gen. de 1511 auf fol. 125 (laut K. Vollmöller in Ztschr. III 84). Es beginnt:

No hallo a mis males culpa, porque en mi terrible pena la causa que me condena me desculpa.

1 Vgl. Miranda No. 164, 332: Em tambem era o juiz.

2 Nachträglich bemerke ich, dafs schon Dom Joam Manoel das alte Lied umschrieben hat. S. Canc. de Res. I p. 410. - D. João de Menezes ist also nicht der Verfasser, sondern nur einer der Beuutzer desselben. 
Auch Montemayor und Gregorio Silvestre haben diese Worte zum Thema für eigene Volten und Glossen gewählt. Man sehe Obras de Nontemayor, ed. 1588 , fol. $39 \mathrm{v}$ und Rivadeneyra Bd. 35 No. 889, wo Silvestres Umarbeitung der Zeilen ins Geistliche abgedruckt steht. In dem Camoens zugeschriebenen Briefe ist die Ausgangszeile wahrscheinlich von späteren Abschreibern, vielleicht aber auch erst vom Herausgeber als eine zu knappe üierarbeitet worden. Man vergleiche Zeile I03. Den kurzen Vers hier wie dort zu füllen, wie Storck es möchte, scheint mir durchaus unnütz. - Auch Ant. Prestes benutzt das Verschen (p. 453).

47-48 Triste del, triste que muere

$\mathrm{Si}$ al paraiso no va.

Woher sie sind, weifs ich nicht. Beliebt und allbekannt müssen sic gewesen sein, denn auch Jorge Ferreira de Vasconcellos verwertet sie in seiner sentenziösen Eufrosina (p. 130) und in seiner Ulysippo auf Bl. I I9v. - Garcisanchez de Badajoz, Rodriguez del Padron, Guevara, Cartagena und Dom João de Menezes sind die meist benutzten und meist citierten Dichter des Cancionero General: in ihren Werken findet sich daher vermutlich auch dieses Citat, wie die übrigen, noch nicht auf ihre Quellen zurückgeführten (in so weit sie nicht dem Romancero entnommen sind).

95-96 Ia no llegará el plazer

Donde llegó la tristeza,

zwei Zeilen, dic Ferreira de Vasconcellos in seiner Ulysippo (fol. 187v) anführt mit der Bemerkung, sie seien von Garci-Sanchez.

I 8-I 19 Las tristes lagrimas mias

En piedras hazen señal

( $Y$ en vos nunca por mi mal).

Fin altes volkstümliches, oft glossiertes Motto. Ich kenne eihe Glosse dazu im Canc. Gen. de 1557 fol. 390, eine andere steht im Canc. de Nágera No. II von Coloma; eiue dritte im Canc. de Oxford (Bd. II p. 83 d. Ztschr.), eine vierte Variation von Gregorio Silvestre in Rivadeneyra Bd. X 35 No. 887 .

I 43-I44 sind ein portugiesisches Sprichwort "Os homens queremos ver, que os vestidos sao de la", das $\mathrm{z}$. B. von Bento Pereira verzeichnct wird, und das Francisco Manoel de Mello in seinen Cartas Familiares p. 348 verwertet.

$$
\begin{aligned}
& 151-152 \text { Por aquel postigo viejo } \\
& \text { Que nunca fuera cerrado. }
\end{aligned}
$$

Fs ist der Anfang einer hochberühmten alten Cidromanze, die man bei Duran unter No. 804 und 1897 findet, und die von portugiesischen Dichtern wie Gil Vicente, Prestes, Ferreira de Vasconcellos oft benutzt worden ist, früher als sie in einc Sammlung aufgenommen ward. Der Reim des portugiesischen pejo mit dem kastilianischen viejo beweist nur noch einmal das längst bewiesene Faktum, dafs das kastilianische $j$ im 16 . Jahrhundert noch portugiesischem gleich lautete. 


\section{9-160 Mirava la mar de España Como menguava y crecia}

sind Zeile 2 und 3 der schönen Romanze, welche dem Könige Alphons IV. von Aragon eine Apostrophe an die Stadt Neapel in den Mund legt (Duran No. 1227 ).

167-168 Tiempo bueno, tiempo bueno

Quien te me llevó d'aqui?

Über diese Romanze habe ich bereits anderwärts gesprochen (Ztschr. $\mathrm{V}$ 77). $\mathrm{Zu}$ dem früher Bemerkten füge ich noch hinzu, dafs sie auch von Simão Machado in seiner "Comedia Alfea" citiert wird (laut Braga, Quinhentistas p. 22), ferner von Ferreira de Vasconcellos in der Ulysippo fol. 103 und von Rodriguez Lobo, Obras p. 749 - Stellen, aus denen hervorgeht, wie beliebt die alte Romanze gerade auf portugiesischem Boden war.

\section{I $83-184$ Mas envidia he de vós, Conde}

Que manzilla ni pesar,

denn also, und nicht Mas he de nos Conde oder mas es de nosotros Conde, wie Storck vorschlägt, muls es heirsen, gemäls der vielgesungenen hochberühmten Romanze vom Conde Claros (Duran 326 nebst Anm. 6, und 363), deren Melodie in Portugal so wohlgelitten war, dafs der Verfasser der Eufrosina von gewissen höfischen Dichtern stichelnd sagen durfte "sie spielten alles nach der CondeClaros-Melodie" (p. 19 und 189).1 Die beiden von Camoens verwerteten Zeilen bilden den Beginn jener bekannten Rede des Pagen, die oft auch als abgesonderte Romanze gedruckt ward und welche Lope de Sosa im Canc. Gen. fol. $202 v$ parodisch glossiert hat (ein Machwerk, welches ebendaselbst wieder von Soria umschrieben worden ist). Man vergleiche auch Salvá No. 2055; IVolf, Studien p. 456 und Prager S. Fl. Bl. p. 86. Das spanische Sprichwort Anles envidia que manzilla ward entweder aus der Romanze abstrahiert oder schon in derselben verwertet.

Acht Citate hatte Storck bereits erledigt; acht andere glaube ich erklärt zu haben; weitere sieben harren noch der Besprechung.

No. XX. Aus welcher Quelle Juromenha den Brief gezogen, weifs ich nicht. Und ob diese Quelle ganz lauter war? Mir ist, als würde Camoens uns tief betrübt und wohl auch etwas verächtlich anblicken, sähe er banausische Brieflein, wie dieser und der vorige es sind, als seines genialen Geistes Kinder betrachtet! ${ }^{2}$ -

' Man vergleiche D. Francisco de Portugal, Prisð̃es p. 23:

$O$ entendimento, que sempre

Se apura nestes estragos,

Hum Conde Claros tangia.

Sem chegar nunci a ser claro.

Auch in Castilien war die Romanze sehr beliebt; die Worte Aqui del Conde Claros dienten im Kampfe der Lopisten gegen die Gongoristen den ersteren als humoristischer Waffenruf.

2 Meine Ahnung hat mich nicht getäuscht. Das oben besprochene Briefchen hat nicht den Lusiadensänger zum Verfasser. Wie ich das erfahren, sei 
In der deutschen Übersetzung klingen übrigens beide edler, voller, gedankenreicher und feinsinniger als in dem hier ganz platten und poesielosen spanisch-portugiesischen Kauderwälsch. Wie im vorigen

kurz gesagt. Im Catalogo dos Manuscriptos da Bibliotheca Publica Evorense tomo II, den ich oft zur Hand nehme, las ich - vor längerer Zeit - auf p. 95 : Trovas de Manuel Pereira de Sem, estando em Arzilla a hü seu amigo que estava em Portugal, em que lhe dava novas de si e da terra. Com. = Mandaste-me pedir novas $=$ Cod. $\frac{\text { (XIV }}{2-2}$ a fol. 141.2 folhas, fol. Letra do principio do seculo XVII. - Ein Briefchen aus Afrika geschrieben, beginnend mit denselben Worten, mit denen Camoens eine der ihm zugeschriebenen Redondilhas eröffnet, das machte mich stutzig, und ich beschlors Handschrift und Druck bei erster Gelegenheit zu vergleichen. Die Gelegenheit bot sich nicht, und so ersuchte ich am 23. Januar Herrn Gabriel Pereira mir freundlichst das fragliche Gedicht zu kopieren und zu senden, was er bereitwilligst und umgehend that. Gestern Abend (27. Januar) erhielt ich die Abschrift - für die ich hiermit öffentlich meinen Dank ausspreche - und erkannte darin das pseudokamonianische Gedicht, das mir so wenig gefallen. In einigen Kleinigkciten weicht der Text ab, der sicherlich besser ist als der von Juromenha bcnutzte: I Mandastes-me - 3 sejam - 5 êmque - 9 Deixando - 12 passo fïr faço - 13 julgai - $14 E$ o que la sentiriu - 15 algüa hora - $16 T_{i-}$ vestes - 19 meu cuidado (?) - 20, a vida mudada, - 23-24 Mas da maa scimpre he figura (? mir scheint die gedruckte Lesart in diesem Falle vorzüglicher) Que da boa etc. - 25 E pois me ja obriguei - 3I Una adarga ante pechos - 36 vento - 37 em que cuido - 39 der Kopist schrieb irrtümlich a miude für span. a menudo - 40 Trabalhando(?) de tarde en tarde. 42 a companhia. - 45 Como me vou alongando - 50 Todos meus vados fundumentos - 53--54 Se alma mais que a vida dura, Mais que a vida ha de durar. (? Auch ich würde wie Storck hao setzen und das Subject dazu in den pensamentos der dritten Zeile suchen) - 64 furamentos - 72 men. sua - 73 que saudade -76 por me anojar - 80 mi - 81 Crêde-me quanto ros falo - 84 do que digo - 85 com a alma - 87 Por el vuestro amor, señora - 92 Que enfim nao funide nada (?? Man erwartet Qu'emfim näo servem de nada. Wahrscheinlich war servem durch die übliche Abbreviatur ausgedrückt) - 99 embraçadas - 100 A flor de la Berberia (sic) - 104 $E\left(I_{)}\right.$encima sus albornozes - $106 E$ de diversas feifzes - 117 festa 120 alabarei (Schreibfehler für alabareis) - 123 Desia quem etc. - $125 E$ pois que - 128 Si en - $133 E$ houve - 144 Do meu amor que la era 145 Quisera dizer-z'os mais - 146 Mas pois - 147 Farei - 148 Entendeime - 150 Que inda d'isto mais dissesse - 152 Puede (vielleicht Puedo?). Üher den Verfasser der "Carta eln Trovas" weils ich nichts zu sagen: Manoel Pereira de Se $\mathrm{m} \cdot \mathrm{ist} \mathrm{mir}$ "als Dichter und Krieger in Afrika gleich unbekannt. Der Familienname Pereira de Sem befremdet mich, und ich vermute, de Sem sei als Abbreviatur zu fassen und aufzulösen in de Sanctarem! Manoel Pereira de Sanctarem klingt schon ungleich echter; mehr denn ein Portugiese dieses Namens hat existiert. - Sind, so vermag ich heute nur za fragen statt selbst dic Antwort zu geben, sind in Evora noch weitere handschriftliche Werke von Manoel Pereira vorhanden? Ich vermute es: auf Seite 95 des oben erwähnten Katalogs stehen nämlich verzeichnet: Poesias de Manuel Pedreira de Sintarem. Cod. $\frac{\text { CXIV }}{1-12}$ d. a fol. 226. An der Existenz eines Manoel Pedreira de Santarem erlaube ich mir ebenso ungläubig zu zweifeln wie an der eines Manoel Pereira de Sem. - Und weiter frage ich: ist Manoel Pereira, der bei Alcacer-Quebrir gefochten (Jeronymo Mendoça p. 11 3; Bayão p. 744 ; Hist. Scb. 443; Barb. Mach., Memorias IV 423), identisch mit unserem Dichter? Gehörte er zu den Pereiras von Santarem? Hatte er in Arzilla gestanden? (S. Souzn XI 936.) Barbosa Machado, Innocencio da Silva kennen den bis heute überhaupt unbekannten Poeten nicht.

Zeitsohr. f. rom. Ph. VII. 
Briefe, so schlielst auch hier eine jede Strophe (mit Ausnahme der einleitenden drei?) mit zwei spanischen Zeilen $a b$, die stets geflügelte Worte sind.

$$
\text { 47-48 Las vozes que iba dando }
$$

Al cielo quieren subir

entstammen der alten, populären Palmsonntagsromanze „Domingo era de ramos" (Duran 394), aus welcher eine andere Zeile Vuella, vuelta a los franceses sehr häufig citiert wird, z. B. von Gil Vicente und Ferreira de Vasconcellos. - Ganz ähnliche Formeln kehren übrigens noch in anderen Romanzen wieder, wie in der von Gaiferos (Duran 377). Daselbst ist nur der Assonanz wegen subir durch llegare ersetzt.

$$
\begin{aligned}
& \text { 63-64 Los ojos puestos nel cielo } \\
& \text { furamentos iva echando. }
\end{aligned}
$$

Sie gehören zur Romanze von Oliveros und Montesinos (Duran $370,53-54)$.

$$
\begin{aligned}
& 71-72 \text { S. oben XIX } 159 . \\
& 79-80 \text { Por el tu amor, señora, } \\
& \text { Passé yo la mar salada. }
\end{aligned}
$$

Señora stelle ich aus dem unsinnigen sen ti ora her. Die Lesart señora scheint jedoch mehr als eine aus Reimesnöthen des Dichters ad hoc gemachte Variante zu sein, da auch Ferreira de Vasconcellos sie in derselben Weise citiert (Eufrosina p. 181 Por amor de vos, señora, etc.). Im spanischen Originale steht freilich der Name der Dame, der schönen Infantin Sevilla (s. Duran No. 373, 85-86).

$$
\begin{aligned}
& \text { 87-88 Vi venir pendon vermejo } \\
& \text { Con trescientos de caballo. }
\end{aligned}
$$

Diese Zeilen gehören derselben Cidromanze an (Duran 804 und 1897), aus welcher in die vorhergehende Nummer (XIX 151) zwei Zeilen eingefügt worden waren.

$$
\begin{aligned}
& \text { 95-96 Ricas aljubas vestidas } \\
& \mathrm{Y} \text { encima sus albornozes }
\end{aligned}
$$

finden sich in einer anderen Cidromanze (Duran $1898,5-6)$.

$$
\text { 103-104 Los bordones que ellos llevan }
$$

Lanzas vos pareceran

vermutlich aus einer heute unbekannten Gaiferosromanze.

$$
\begin{aligned}
& \text { 120-121 A las armas Moriscote } \\
& \mathrm{Si} \text { en ellas quereis entrar }
\end{aligned}
$$

sind überaus bekannt und oft als Citat benutzt worden, parodiert z. B. in den Autos von Prestes p. 190 ás pancadas, moriscote; doch ist die Quellenromanze nicht oder wenigstens nicht vollständig erhalten. F. Wolf sagt richtig, sie komme in keiner der bekannten Sammlungen vor, und verzeichnet sie daher in dem Quodlibet aus Romanzen und Liederanfüngen, welches seinem Briefe über die Prager Sammlung fliegender Blätter zur Finleitung dient, mit einem Sternchen. Daselbst lautet die zweite Zeile

Si las has en voluntad. 
Ein etwas umfangreicheres Bruchstückchen (sechs, vielleicht sogar zehn Zeilen) enthält das Libro de Musica para vihuela des Miguel de Fuenllana, Sevilla 1554 (s. Salvá II p. 340 No. 25 I5).

\section{8-129 Donde estás que no te veo?}

Que es de ti, esperanza mia?

Von den zahlreichen Volten und Glossen zu dem, wie so viele andere, höfischen Kreisen entsprossenen und doch echt volkstümlichen Thema hat Storck bereits vier angeführt. Auch Gil Vicente citiert das Thema (II 329), dessen zweite Zeile von den „Flickschneidern", die es ihren Gedichten als bunte Lappen anhängen, je nach dem Reimbedürfnis verwandelt wird in alma mia que es de ti oder que es de ti, esperanza mia.

\section{$136-137 \mathrm{Y}$ que nuevas me traedes}

(Del mi amor que alla era?)

Die erste der beiden Zeilen findet sich in der Romanze von der schönen Maurin und Alfonso Ramos (Duran 4, 13), doch heifst es weiter darin :

Am portugiesischen Texte bleibt noch manches nachzubessern. In Zeile 5 würde ich $\hat{E} m q u e$ statt $E$ que lesen. - 14 Storcks Vorschlag, $D^{\prime}$ isto an Stelle von $D_{0}$ zu setzen, um den zu kurzen Vers zu füllen, ist darum unannehmbar, weil von fernliegenden und nicht von örtlich und zeitlich naheliegenden, gegenwärtigen Empfindungen die Rede ist. Besser scheint mir zu setzen $D_{0}$ que la eu sentiria oder $E$ o que la sentiria. - 15 Die Schreibweise algu' hora ist verkehrt, die alten Handschriften lassen durchgängig algũa hora unverkürzt. - 16 Tive este ist vermutlich durch Tivesse (ich hätte) oder Tivestes (ihr hattet) $\mathrm{zu}$ ersetzen. - 37 Vou-me traz isto em que ando soll ein Camoens geschrieben haben! ando ist sichtlich verderbt, da die Zeile Suspirando a menudo darauf reimen muls. Storck schlägt vor, um diesen Fehler zu beseitigen, $A$ menudo suspirando $\mathrm{zu}$ lese. $\mathrm{Ob}$ es nicht besser ist diese Zeile unberührt zu lassen, statt ando aber cudo (cuido) $2 \mathrm{u}$ setzen? - In 42 steckt unbedingt ein Fchlcr. Doch welcher? - 100 ist eine spanische Zeile mitten im portugiesischen Texte. - 117 Man lest festa statt festas. 120 alabareis für allabareis. - $128 \mathrm{Nicht} S^{\prime}$ in, wie Juromenha druckte, und nicht $S^{\prime}$ en, wie Storck berichtigt. Man drucke und lese Si en: beide Vokale müssen hörbar, also auch sichtbar sein.

No. XXI. Von diesem Briefe gilt dasselbe, was ich zu No. VIII bemerkte, dafs nämlich die Handschrift, welcher Juromenha das bislang unbekannte Stück entnahm, dafs also die Miscellanea, welche seinen Namen trägt, kein Wörtchen über den Autor des Briefes verliert. Auch hier hat den Herausgeber die Thatsache, dafs der in Wahrheit kamonianisch klingende Brief unmittelbar auf eine dem Dichter gehörige und ihm auch von der Handschrift zugesprochene ähnliche Liebesbotschaft (No. XXIl) folgt, zu seiner unbewiesenen Behauptung verleitet. Sein Abdruck ist nicht sehr 
sorgfältig ausgefallen, wie meine Berichtigungen (Ztschr. IV 604) gezeigt. Einiges ist noch zu erledigen. In Zeile 7 wird es gut sein poderes an Stelle von poder zu setzen; eine Änderung, durch welche der Vers nicht überzählig wird, da es erlaubt ist Gebrauch zu machen von der allbekannten Licenz, Pra für para zu lesen (vgl. Zeile 9, 1 2, 13, I5). - In Zeile I 8 steht pera und nicht por in der Handschrift. - Zeile 19 und 20 sind mir unverständlich und scheinen verderbt. Storcks freie Interpretation „Ungezïhlt sei'n deine Zähren, Meine Weh'n nicht unerzählt" scheint cine glückliche zu sein, giebt aber keine Handhabe zur Verbesserung des Originals. - Zeile 2 I mufs bei einer zweiten Auflage des Buches der Lieder umgearbeitet werden, da das Original nicht chorando sondern chegando hat. - 30 Ich würde lesen Por hũa lam gram belleza. Es ist wahrscheinlicher, dafs der Kopist irrtümlich gra zu grandt erweitert hat, als dafs er nhĩa durch por hũa ersetzt habe, wie Storck annimmt. - 63 Macias hält bis zur Todesstunde den Namen des Geliebten im Herzen, in der Erinnerung fest, na mente, wie das Original sagt (statt na morte). Ein Hinweis auf Uhlands schöne BaHade wäre dem deutschen Publikum gegenüber in der Biographie des verliebten Portugiesen wohl angebracht gewesen.

No. XXII. Zeile 17 scheint mir verderbt zu scin: ich schlage vor fica an Stelle von vica zu setzen. - 67 Der Vers ist zu lang, wenn nicht der Nasal von nao elidiert wird. - 71-75 Der Gedanke des Originals ist gewifs vom deutschen Dichter fein und rein nachempfunden und ausgedrückt worden (ein anderer pafste kaum in den Zusammenhang); die grammatische Konstruktion des portugiesischen Textes bleibt mir aber trotzdem unklar, - 94 Im Ms. steht vendido; Juromenha ändert rendido, ich würde vencido vorzichen.

No. XXIV. Den Titel Disparates na India übersetzt Storck mit „Narrheiten in Indien“. Frsichtlich ist aus dieser Verdeutschung nicht, dafs der Portugiese, wie der Spanier, unter Disparate cine besondere, humoristische, oft auch satyrische Dichtgattung versteht! In Wörterbüchern und Poetiken sucht man freilich vergeblich nach Auskunft über dies Genre, und es ist sehr wohl möglich, dafs Storck den Doppelsinn, der in der portugiesischen Überschrift steckt, nicht empfunden hat. Disparale bedeutet cousa dita sem proposito, sem o modo e o fim devido, auf deutsch also „ungereimtes und doch gereimtes Zeug“, „närrische Finfälle“, absichtlich sinnlose Reimspiele, Quodlibets (coq-d -l'(ine); und das Figentümliche der so betitelten Dichtgattung, die jegliche metrische Form annehmen oder auch in Prosa auftreten kann, besteht darin, dals entweder in freier Gedankenassociation die heterogensten Dinge zu einander in eine scheinbar motivierte Beziehung gesetzt oder ganz lose an einander gereiht werden; oder darin dafs lauter solche Worte in den Text hineingeflochten werden, dic einer mehrfachen Auslegung fähig sind. Zuerst wird dann das Wort in der einen, gewöhnlich der ursprünglichen, Bedeutung angewandt; der nachfolgende Zusatz 
aber wird auf eine ganz verschiedene Anwendung bezogen, und es entstehen so burleske Witze mit widersinnigen Kontrasten, bei denen der Reiz des Lächerlichen eben im Widersinnigen gefunden wird. Oder aber er besteht darin, dafs allbekannte Phrasen und geflïgelte Worte zusammengestoppelt und gleichfalls in anderem als ihrem ursprünglichen Sinne verwertet werden. In allen drei Fällen wird eine komische Wirkung beabsichtigt und meist auch erreicht; am besten, wenn auch am gröbsten, da wo Wortspiele den eigentlichen Gehalt des Stückes bilden, also in den Dichtungen nach der zweiten Manier.

Augenblicklich kann ich nur auf je zwei Probe- und Beweisstückchen für die beiden ersten Kategorien hinweisen. Für die dritle aber sind die "Disparates na India“ der einzige mir bekannte poutische Beleg.

Komisch wirkende Gedankenassociationen bilden den Inhalt der „Disparates compuestos por D. Pedro Manuel de Urrea“ (Bibl. de Escritores Aragoneses. Seccion litt. Tomo Il. Cancionero de Urrea p. 166, Zarag. 1878) und des „Romance de disparates de Diego de la Llana“ (Duran No. 1887; cfr. No. 1874, I875).`

Wortspiele sind der humoristische Kern der „Novela disparatoria do gigante sonhado por A. S. C.“ (Lisboa I745) und eines Zeitungsinserates im „Folheto de ambas Lisboas“ (No. 3, Lisb. 1 730). Um dem Leser zu zeigen, um welche Art von Witzen es sich darin. handelt, citiere ich je einen Satz aus beiden Volksschriften. In der ersten heifst es bei Gelegenheit der Traumschilderung des Riesen: o seu rostro era de çapalo; a cabeça de Monte-Achique; hum olho de couve; outro de alface; a boca de forno; os beiços de alguidar; os denles de serra; as pastanas de vestido; huma mato de papel, e outra de almofariz; hum pé de cravo, outro de cantiga; os braços de mar etc. In der zweiten heifst es: Huma trevoada exicessiva, que deu com huma grande chuta, fez huma lal enchurradi nesta rua que causou admiraçà a lodos os visinhos, pelo disiostume; e depois de cessar se vio na boca do cano num cadazer de extranränaria grandeza. que se nav conheceo peias istranhas feicoens; porque a cabega era da saude; os olhos hum de couve, outro de agua; a boca de Sacavem; as barbas de

1 Dem Titel, aber nicht dem Inhalt nach, sind mir noch verschiedene andere Disparates bekannt: Almoneda de disparates, nuevamente hecha; en coplas que dizen: „En la tarde hay almoneda". Pliego Suelto $\sin$ L. ni A. Glosa jocosa á modo de disparates, becha al romance de: „Tiempo es el caballero"; en coplas que dicen: „En danza mil putas viejas". - Disparates de Gabriel de Saravia, muy graciosos y apacibles para cantar, glosando muchos viejos romanzes. - Disparates muy graciosos y de muchas suertes hechos, y un aparato de guerra que hizo Montoro, y unos fieros que haze un rufian. - und vor allem die Disparates y almoneda trabados por Juan de Encina. Diese letzteren waren ohne Zweifel die beliebtesten und bekanntesten Ungereimtheiten; in spanischen und portugiesischen Dramen begegnet man oft Phrasen wie mas disparates no dijo fman del Enzina (s. Moreto, Antioco y Seleuco und Jorge Ferreira de Vasconcellos, Ulysippo fol. 214v). Laut F. Wolf, Studien p. 203 und 273 stehen auch im Cancionero de Baena zwei Disparates trobados unter No. 99 und 106. 
balea; os bragos hum de mar, oulro de viola; as maos huma de rabaos, outra de papel e finalmente os pis, hum de cantiga, outro de cravo etc. 1

Die Disparates des Camoens nun bringen die eigentümliche Lachwirkung, auf welche auch sie abzielen, wie bereits gesagt ward, in anderer Weise als die eben kurz verzeichneten „Ungercimtheiten in Reimen" hervor. Sie stehen dem bekannten Genre der „Fnsaladillas" 2 und der "Centð̋es" und der "Cartas de girôes" nahe, da sie, wie alle diese, ein Potpourri aus entlehnten Versen, aus bekannten Sprichwörtern und vulgären Redensarten sind, mehr wahrscheinlich noch als wir es heute, nach drei Jahrhunderten, bei mangelhafter Sachkenntnis, $z u$ ahnen im Stande sind. ${ }^{3}$ In den „Disparates da India“ steht die Schlufszeile aller Strophen aufserhalb des metrischen Rahmens, d. h. sie ist nicht durch den Reim mit den übrigen 9 Strophenzeilen verbunden, und weicht, was Rhythmus und Silbenzahl betrifft, von ihnen ab; sie ist, oder klingt doch, wie reine Prosa. Aufserdem sind spanische mit portugiesischen Brocken in absonderlicher Weise gemischt.4 Die bunte Wirkung, welche diese beabsichtigten Unregelmärsigkeiten erzeugen, läfst sich

1 Mussafia hat 1867 aus einer Handschrift der Wiener Hofbibliothek einen spanischen Brief veröffentlicht, der ganz und gar aus solchen Wortspielen besteht, dem aber im Titel nicht das Schlagwort "Disparates“ gegeben ward. Der Vergleich mit den portugiesischen Stücken ist lehrreich.

2 Die „Ensaladas“ mischen Reime aus den verschiedenartigsten Gedichten, in den verschiedenartigsten Metren, aber auch in zwei oder drei verschiedenen Dialekten unter einander. Ich kenne solche „em mourisco, portuguez e bis. cainho". - Ein sehr interessanter "Flickenbrief" steht in der Aulegraphia fol. 99. Er besteht aus italienischen Sätzen Dantes und Petrarcas und lateinischen aus Ovid, und schlägt, wie ein echter und rechter Flickenbrief mufs, „mehr krause Wellen als der Nordwest".

3 Es muls damals Mode gewesen sein "Cartas de Disparates" in Prosa und in Poesie an gute Freunde zu senden. Erzählt doch Rodriguez Lobo in seinem "Höfling" (Corte na Aldeia p. 25 der Obras): ha outra (especie de' cartas) de disbarates que parecendo que se desviao nas palavras do propusito que tomalo, dao a entender como em enigma o pensumento de quem as escreve, e sao estas graciosas com sutileza; und weiter: é certo que nisto tiverao mão particular os Portuguezes que escrevéráo ao gracioso, que nem os Italianos na frasi burlesca nem os Hespanhoes no estilo picaresco is igulárao. - Wären nur erst mehr Probestücke bekannt!

- Storcks Bemerkung ,der Dichter habe vielleicht die damalige Rede des Tages in Goa kopiert und parodiert" scheint mir in höchsten Grade unwahrscheinlich. Diese mufs unendlich viel barbarischer, verderbter und roher gewesen sein, wie aus aller Zeitgenossen Klagen hervorgeht (João de Barros; Ferreira de Vasconcellos). - Die willkürliche Mischung von Spanisch und Portugiesisch aber beschränkte sich keineswegs auf Goa (wenn sie überhaupt dort Mode war); sie war in Portugal selbst, wie die ganze quinhentistische Litteratur, vor allem aber der dramatische Teil derselben, auf das sinnfälligste zeigt, an der Tagesordnung und bei hoch und niedrig gleichmälsig zur Gewohnheit geworden - eine auf ganz naturgemärse Weise entstandene Gewohnheit, die wir, so gern wir es möchten, doch nicht als Unsitte bezeichnen dürfen. Einen ästhetisch reinen Eindruck kann ein mehrsprachiges Gemisch freilich nie machen, und Camoens bat sich selbstverständlich auch gehütet 
im Deutschen nicht wiedergeben. Der Übersetzer hat es, mit Recht, für mirslich crachtet hie und da dialektische Formen einzustreuen. Weniger stimme ich damit überein, dafs er alle die Sprichwörter, welche den Schlurs von Strophen bilden, durch eigens erfundene und in sich gereimte Nachbildungen ersetzt hat. Ein ungefähr gleichwertiges, aber wirklich bestehendes ound, was die Hauptsache ist, allbekanntes, drastisch derbes, deutsches Sprichwort in Prosa würde mir besser gefallen und den humoristischen Effekt sicherer hervorrufen, auf den es in diesen Ungereimtheiten nun doch einmal ankommt. Wie Prosaiker und Blankversdichter hie und da eine starke und unerwartete Wirkung durch plötzliches Einstreuen von gereimten Zeilen erzielen, so erzielt sic der Dichter hier durch ein plötzliches Aufgeben des Reimes wie des Rhythmus. Natürlich ist dic Wirkung aber eine gerade entgegengesetzte, dort ein Erheben in alle Himmel, hier ein Herabreifsen aus allen Himmeln.

Nur die ersten neun Strophen halte ich für echt. Den letzten acht fehlt es, wie Storck bemerkt, an Schlagfertigkeit und Schärfe; auch richten sie sich formell nicht immer nach den oben aufgestellten Regeln; auch sind sie durchgehends in reinem Portugiesisch geschrieben. ${ }^{1}$

Ich bin nun keineswegs im Stande die Quellen aller derjenigen Zeílen zu nennen, die mir entlehnte zu sein scheinen, und glaube auch nicht, dafs es irgend einem Anderen gelingen wird sie ausfindig zu machen: denn die Mehrzahl der Zeilen sind stereotype Redensarten, deren Einzelurheber nicht aus der grofsen Schaar der Nachsprecher gefunden werden kann. In Strophe I halte ich z. B. aufser 1 und IO, die Storck schon als erborgte nachgewiesen hat, auch Zeile 2 Ado hay duzientos vaos (sic) ${ }^{2}$ und 4 Todos somos del

es zu anderem als zu humoristischem Zwecke darzubieten. - Man vergleiche auch seine lustige Einsprache, selbst gegen lustige Anwendung der Flickentheorie in seinen Amphitriðes (ed. Braga, p. 110):

$$
\begin{aligned}
& \text { Que a trova trigotremez } \\
& \text { ha de ser toda d'hum panno! } \\
& \text { que parece muito ingrez } \\
& \text { n'um pelote portuguez } \\
& \text { todo hum quarto castelhano! }
\end{aligned}
$$

1 Auf das Seltsame, was darin stecken soll, dafs der Dichter in Vers 147 dem Leser den Rat erteilt „ein dreifsig oder vierzig Reime“ zu überschlagen, während nur noch 27 übrig seien, lege ich kein Gewicht. Der Dichter sagt tres ou quatro trovas; unter trovas können aber ebenso gut Versueilen wie ganze Strophen verstanden werden: es existieren einstrophige und doch trovas überschriebene Lieder genug. Freilich wäre demjenigen, welchem die Ungereimtheiten zu lang däuchten, mit dem Überschlagen von drei oder vier Zeilen wenig geholfen! Aber in der Unzulänglichkeit des vorgeschlagenen Heilmittels kann vielleicht gerade der (recht schaale) Witz stecken!

2 Die Übersetzung dieser Zeile scheint mir mifsglückt. „Einer Strafse gleicht die Erde"“ - nicht rauh, beschwerlich, steil und eng -, sondern einer Strafse, die zweihundert verschiedene Übergangsstellen bietet, wo also jedermann, ob gut ob schlecht, ob reich ob arm, ob hoch ob niedrig, sich seinen eigenen Weg sucht: 
merino ${ }^{1}$ und in 8 das dejadlos mi madre für sprichwortähnliche volkstümliche Redewendungen. Dasselbe gilt von 50 Assi entrou o mundo, assi ha de sahir, das Camoens selbst in seinem Prosabrief (No. 158 Z. 221 ) wiederholt und das vor und nach ihm sattsam genug gepredigt worden ist; und von 6o cobrir o cen com huma jocira und von 69, wo tempo de figos auf das Sprichwort em lempo de figos não ha amigos hinweist; und von 84 fazer a justiça de teas de aranha. Wirkliche Citate stecken in Zeile 13 und It Villas y castillos lengo, Todos a mi mandar sone. . Sie gehören der Romanze von Fernan Gonzalez an (Duran 704, 25-26), aus welcher auch die sprichwörtlich gewordenen Verse stammen:

Mensajero eres, amigo,

No mereces culpa, no.

Zeile 33 und 34 kehren in den Romanzen von der Belagerung Zamoras wieder (Duran 776 und 1895). Zeile 78 bietet ohne Zweifel ein bekanntes und volkstümliches spanisches Lied. Wo ich es gelesen, weifs ich freilich nicht $z u$ sagen; wohl aber dafs der citatenreiche Possenschreiber Antonio Prestes zwcimal dieselbe Zeile wie Camoens benutzt: auf S. I7 und I05 Que nel campo dormiris Que no comigo. ${ }^{3}$ Die spanische Zeile 101 Ado lienen las mentes erinnert mich an ein Villanceio von Bartolomé Santiago, welches beginnt Do tienen oder Do ticnes las mentes (Duran I p. LXXIV); andere erinnert es vielleicht an andere Lieder. und 88

Noch habe ich einige Bemerkungen auf dem Herzen: Zeile 87

Para os pequenos huns Neros,

Para os grandes tudo feros

scheinen mir zwar hübsch und munter, aber nicht richtig wiedergegeben durch

An den kleinen ziehn und zerren

Und berupfen grofse Herren.

Das Gegensätzliche beider Zeilen ist unbeachtet geblieben, obwohl doch die leeren Prahlhänse in der kamonianischen Phrase so kernig charakterisiert sind „Den Kleinen gegenüber sind sic: kïhn in 'Thaten, wahre Nerone; den Grofsen gegenüber bleibts bei citlem Drohen und Prahlen". - Mit feros wird noch heute alles grofsmäulige Bra-

1 Diese Phrase - die vielleicht einem alten Schäferspiel entstammit? war bei den Quinhentistas sehr beliebt. Allein bei Jorge Ferreira de Vasconcellos, dem spruchreichesten unter allen, begegne ich ihr vier mal: Ulys. 113 . 201. 261 und Eufr. p. 23, und wird sie daselbst als palavra corriquirira per que todo o mundo passa d.h. also als Allerwelts - Weisheitsspruch, als hausbackene Wahrheit bezeichnet. - Die betreffende Stelle der Ulysippo ist charakteristisch: ein Kavalier, der dic Belagerung von Mazagão mitgemacht hat, lärst sich einen Rundschild machen, auf welchem Herkules mit sciner Keule vor den, vom Drachen hewachten, goldenen Hesperidenäpfeln dargestellt ist. Darunter die Inschrift Tudos somos del merino, was doch nichts anderes bedeuten kann als anch'io sono pittore "Auch ich ward in Arkadien geboren" d. h. „auch ich bin Afrika, dem Atlas nahe, gewesen wie Du, oh Herkules".

"Camoens citiert dasselbe Liedchen noch (wie Storck bemerkt) in einem seiner Prosabriefe CLVI, 141 und ferner in den Amphitriợes ed. Braga p. 149. 
marbasieren bezeichnet, das der Portugiese übrigens, nebenbei bemerkt, für die hervorstechendste Eigenschaft des Kastilianers hält, während dieser dem verhafsten Mitbesitzer der iberischen Halbinsel seine Verliebtheit, Phantasterei und Weichlichkeit vorwirft. ${ }^{1}$ - Dals in Zeile 90 das Sprichwort la valo licis onde querem reis durch die Censur zu la vaio reis onde querem cruzados verändert worden sei, scheint mir unglaublich. Ein in aller Welt Munde kursierendes, tausendmal im täglichen Leben citiertes Sprichwort, mit Aufhebung der darin steckenden Reimformel, im Ernste modifizieren zu wollen, ist ein Unterfangen, das man selbst dem Büchercensor nicht zutrauen darf, am allerwenigsten in einem Lande, wo der Satz „Sprichwörter seien kleine Evangelien" von jeher Geltung gehabt hat. Nur als Witz (und die Witzform, in allbekannten Phrasen ein erwartetes Wort durch ein unerwartetes zu ersetzen, ist ja auch heute noch beliebt), und zwar nur als vom Dichter selbst gemachter Witz, ist die Metamorphose von reis zu cruzados annehmbar. Eine doppelte satyrische Pointe steckt natürlich darin: erstens, Geldmacht geht über Fürstenmacht, wic um die Mitte des I6. Jahrhunderts tausend Zungen klagten; und zweitens, die kleine Münzsorte der Kupferreis ist jedoch bereits machtlos, Silber-cruzados haben ihre Stelle eingenommen.

$\mathrm{Ob}$ die Übersetzung der 116. Zeile die Intention des portugiesischen Originals klar macht? Morto por desenterrar Parentes que cheiram $j a$ bedeutet doch nur, dafs der Emporkömmling aus niederer Abkunft tödtlich oder sterblich darauf erpicht ist, alte, Verwesung duftende, unkenntliche Ahnen aus dem Grabe der Vergessenheit aufzuwühlen und auszuscharren. - Zu Zeile I 30 bemerke ich, dafs unter dem Sprichwort, auf welches angespielt wird, vermutlich Quem mente, arrede testemunhas zu verstehen ist, dafs der Dichter es aber zu seinem Zwecke umgemodelt hat in Quem nato mente, não arreda testemunhas mit einem bösen Seitenblick auf die ohne Zeugen d. h. in der Beichte gesprochenen Wahrheiten.2 Über Vers 150 habe ich schon früher gesprochen ("Ltschr. IV 602): eine Variante des betreffenden Sprichwores Quem porcos busca a cada mouta the grunhem ist manchem behufs Sicherstellung der von mir gegebenen Deutung vielleicht erwünscht. Sie steht in der Ulysippo fol. $132 \mathrm{v}$.

Dafs trotz der humoristischen Form des Gedichtes sich dennoch ein gut Teil ernster Satyre darin verstecke, leugne ich übrigens nicht; doch ist sie keineswegs sehr scharf und vor allem wenig individuell; dieselben Disparates, welche: Camoens als indische geifselt, sind zur gleichen Zeit von anderen Portugiesen, als heimatliche und gleichfalls als indische, mit gröfserer Kraft ange-

1 S. z. B. Aulegr. p. 128: (Los Portuguezes) no saben mas que hablar "minha fermosa". E Castelhanos subem mais que rebolarias e feros $F$

2 Jorge Ferreira de Vasconcellos beginnt und unterbricht in der Eufrosina p. 71 das Sprichwort in gleicher Weise. Anderwärts citiert er vollständig Quem quiser mentir, arrede testemunhas. 
griffen und an den Pranger gestellt worden. Dafs dies Gedicht ihm gerade besondere Feinde und Feindschaften in Goa zugezogen haben sollte, wie noch immer behauptet wird, scheint mir sehr unglaublich.

No. XXVI. Vers 8 und 9 bergen in sich in der That eine Allusion auf ein Sprichwort, oder gar auf zwei. Diese heifsen Morra Martha e morra farta, und Bem canta oder Bem palra oder Bem prega Martha depois de farla. Eine Erinnerung an die typische Gestalt der frommen d. h. scheinfrommen Martha (Narla a piedosa oder Martha piadosa que dava o caldo aos enforcados), die Tirso de Molina z. B. zum Gegenstand einer seiner Komödien erwählt hat, mufste und sollte wohl dabei durch jedes Spaniers Gedanken zichen. Man verwechsele nicht die biblische, fleifsige Martha a solicita Martha mit der scheinfrommen. - Wie prächtig ist übrigens auch diese kleine Bittschrift dem Übersetzer gelungen!

No. XXVII. Wie prächtig auch das lustige Gelegenheitsgedicht! Schade, dafs das allerliebste Menu nicht ganz treu übertragen werden konnte. Es ist im Portugiesischen doch noch graciöser und einleuchtender und natürlicher, weil seine Anordnung genau den wirklichen Speisezettel nachahmt:

$$
\begin{aligned}
& \text { Tendes, } \\
& \text { nemigalha - assada } \\
& \text { cousa nenhuma - de molho } \\
& \text { E nada - feito em empada etc. }
\end{aligned}
$$

Caparica in Zeile 23 ist, wie jeder Leser vermuten mufs, thatsächlich wegen seines schönen Rebensaftes berühmt.

No. XXVll. Ich habe gegen die Übersetzung von fios seccos nichts einzuwenden. Dafs es jedoch sehr wohl "Dürrefäden“ im Sinne von "Hungerleider" heifsen könne, beweist eine Stelle aus Soropita p. 83, wo dieser von solchen, welche das ganze Jahr Hunger leiden, am Fastnachtsabend sich aber gütlich thun, sagt: todo anno estao de fios seccos para aluella conjunç̧ao.

No. XXXVIII. Montemayor hat dasselbe Thema wic Camouns glossiert (Ed. 1588 fol. 40). Beide aber haben es aus dem Canc. Gen. 1511 geholt, in dem bereits der Marquis von Villafranca es benutzt und Quiros es mit 18 Zeilen umschrieben hatte (No. 329 und 592 der Ed. 1882 ).

No. XLIX. Zur Geschichte von Justa fue mi perdicion kann ich, wie jeglicher, der die alten Cancioneros oft in die Hand nimmt, einige Beiträge liefern. Aufser der Volta von Jorge Manrique, welche im Canc. Gen. de 1557 auf Blatt I 80 v steht (No. 329 in der 21 . Publikation der Bibliofilos Españoles), bietet dasselbe Liederbuch auf Bl. 252 noch eine andere von Costana (handschriftlich in Evora $\frac{\text { (xIV }}{2-2}$ fol. 136); wieder eine andere dichtete Montemayor, ed. 1588 fol. 36; noch eine a lo divino Gregorio Silvestre, Rivad. 35 No. 884 . - Was mochte alle diese Dichter zur Wiederaufnahme des abgenutzten Themas bewegen? Mir däucht, sie seien alle irgend einer 
Dame, Jusla benannt, zugethan gewesen; wie wir solches mit Bestimmtheit von einem Benutzer des Mottos wissen, von D. Joào Manoel $(\dagger 1476)$, der, nachdem seine Liebe zu D. Justa Rodrigues Pereira (der Amme des Königs Emanuel und Stammmutter der Manoeis) sich in Hals und Reue verwandelt hatte, das Motto annahm Jusla fue mi perdicion (Caet. de Sousa, Hist. Gen. XI 388).

No. L. Dasselbe Motto steht glossiert in den Ineditos de L. Caminha II 240 unter dem Titel Quintilhas de um fidalgo porluguez captivo em Berberia depois da infeliz perda do Senhor Rei D. Sebastião.

No. LII. Der Anlafs zu der bekannten, von Castilho herrührenden Auslegung, der Dichter habe diese Verse auf sein eigenes Portrait gemacht, dando uma navalhada no rosto de uma sua imagem a que faltuva cerla cicatriz, möchte darin zu suchen sein, dafs Pedro Jozé Suppico in seinen Apothegmas (Coimbra 1761) zwei ähnliche Anekdoten erzählt: I) D. Louren fo Arcebispo de Braga, mandou lavrar a sua sepultura na $S e ́$ da mesma cidade, e sobre ella a sua estatua vestida de pontifical. Vindo ver a obra, e advertindo que a estatua não tinha figurada no rosto huma cutilada, que elle recebera na batalha de Aljubarrota em defensa da patria, pedindo huma espada lha deo por aquella propria parte, e disse: Agora sim que fica ao natural. Die zweite betrifft das kamonianische Gedicht noch näher. Sie behauptet (I I64), der Herzog von Bragança, D. Theodosio II., habe Francisco Rodriguez Lobo hochgeschätzt und dessen Bild in seinem Palast aufgehängt. Der Dichter aber habe das Fehlen einer Narbe im Gesicht bemerkt, selbige durch einen Messerschnitt angebracht und dabei deklamiert:

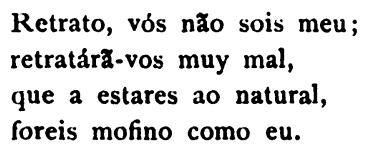

Citierte er das kamonianische Lied aus dem Gedächtnis? oder sollen die Zeilen für sein eigenes Machwerk erklärt werden?

No. LIV. Mir scheint es nötig, die ersten fünf Zeilen der vierten Strophe mit den ersten fünf der dritten zu vertauschen. Anderwärts (Ztschr. VII p. 96 No. 2 I) habe ich gezeigt, dals das im Cancioneiro de Evora erhaltene Lied, welchem Camoens das Motto entlieh, wahrscheinlich von D. Francisco de Portugal, erstem Grafen von Vimioso ist; und dafs, aufser Lobo, auch noch Francisco de Sâ e Menezes dassclbe zum Gegenstand einer hübschen Glosse gemacht hat.

No. LVIII. Ob das Motto ursprünglich spanisch oder portugiesisch ist, weils ich nicht. Camoens und Diogo Bernardes glossieren die portugiesische Fassung desselben; Pedro de Padilla, Canc. p. 499 hingegen glossiert die spanische:

Sin vos $y$ con mi cuidado

Mirad con quien, y sin quien. 
No. LXII. Im Index da Livraria de MIusica de D. João IV. (Ed. J. de Vasconcellos) steht auf S. 264 unter den Villancicos de Navidad ein solches Weihnachtsliedchen von Francisco Barca komponiert, welches beginnt: Tende, Amor, mado, nelle. Ob dieser Francisco Barca nun etwa das Liedchen des Camoens in Musik gesetzt hat, oder ob beide ein ursprünglich populäres aus dem Volksmunde aufgelesen haben, mufs dahingestellt bleiben.

No. LXXV. Amor louco ist ein Sprichwort: überall wo es als solches citiert wird, ist diese Anrufsformel nicht verdoppelt. Die Verdoppelung haben erst die Dichter vorgenommen, die es zum Vers erheben wollten.

No. LXIX. Über Jorge da Silva spreche ich in einer Anmerkung zu Oktave VII.

No. LXXVI. D. Francisco Nanoel de Nello hat dasselbe Thema behandelt (Seg. Tres Musas. Thalia p. 205).

No. LXXXII. Der Name Quaresma ist noch immer üblich und durchaus nicht selten. Dafs der Erzpriester de Hita viel mit D. Quaresma zu thun hat, ist bekannt. Auf die Frage: war das Weib Fastens Frau? wird jeder Portugiese Nein antworten. Azoular ist eine öffentliche Strafhandlung von Seiten eines Beamten.

No. LXXXVI. Dies Liedchen ist im Portugiesischen überaus schelmisch, naiv und lieblich; und mir scheint als hätte es von seiner Anmut im Deutschen verloren, weil der Ausdruck nicht einfach und schlicht genug gewählt ist. Wozu eine Perle noch in Gold fassen?

No. XCV. Das Thema ist jedenfalls ein fremdes und mufs zu den bekannteren gehört haben. Prestes erwähnt es in seinen Autos p. 247.

No. XCVill. Die dritte Zeile dieses zweifellos dem Volksmunde entnommenen Mlottos verwendet Lobo, sic leicht variierend, noch mehrmals. So p. $36+$ mais humilde e mais segura. Nan vergleiche auch Mello, Cartas Familiares p. I05: andar humu crialura sem amor he pouco menos que andar desialsa, trajo que ali cm Lianor quando hia para a fonle descalfa pela verdura me fazia arripiar o cabello.

No. C. Dic Annahme Bragas ist thatsächlich eine irrige. In F. R. Lobos Werken kommt "Leonore am Brunnen" nicht vor. Er verwechselte das von Camoens auserlesene bis ins 18. Jahrhundert hinein populäre, oft glossierte Liedchen

$\mathrm{Na}$ fonte está Leonor

mit einem anderen, ebenso volkstümlichen, welches lautet:

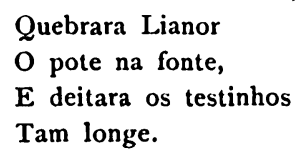

Dieses. letztere hat der Verfasser der Primaveva auf p. 315 und aufser ihm z. B. noch D. Francisco de Portugal (Divinos y humanos versos p. 78) benutzt. 
No. CV. S. meinen Aufsatz über Palmeirim in Ztschr. VI 217. No. CXVII. So sinnreich auch Storcks Auslegung ist, der ich zuerst gern beigestimmt, so glaube ich sie nach reiflicherer Überlegung nun doch abweisen zu müssen. Von einem zu des Dichters Zeiten vielgenannten Liebespaare Mendes-Gonçalves kann kaum die Rede sein, weil keine Spur von seiner Existenz zu entdecken ist. Kein einziger unter all den allusions-, citaten- und anekdotenreichen Zeitgenossen des Camoens gedenkt desselben. Bei einem kleinen Volke aber, das den Beinamen des „verliebten" trägt ${ }^{1}$, und wieder und wieder mit Stolz auf seine Treue, seine Schwärmerei, seinen Enthusiasmus hinweist, und wieder und wieder die Namen derer preisend nennt, die vor Liebe starben und vor Liebe den Verstand verloren haben, da würde sich wohl unbedingt durch schriftliche Aufzeichnung die Nachricht von einem sprichwörtlich gewordenen Liebespaare erhalten haben.

Ich versuche eine andere Auslegung: Gonçalves ist - wie ja

1 Die Beweise für diese Behauptung sind unschwer zu finden: aus dem Munde der Spanier tönt tausendfach variiert das Lied von ihrer Schwärmerei, ihrer Sehnsucht, ihrer Liebestreue. Gilt das Wörtchen saudades nicht für unübersetzbar? Wurden von den alten Portugiesen wohl je andere Poeten gepriesen als solche, die um ihrer Liebesthaten willen Ruf und Ruhm erlangt? Macias; Garcisanchez de Badajoz; Ruy de Sande; Petrarca; Garcilaso; D. João de Menezes? Strebt nicht selbst Camoens unaufhörlich und inbrünstig danach, den Treuverliebten beigezählt zu werden? - Einige noch nirgends verzeichnete Beweisstückchen stelle ich hier um der Kuriosität willen zusammen :

Moraes, Palmeirim III 71: e como de seu nutural (portuguezes e castelhanos) tenham a condiçam namorada, em especial os portuguezes.

Tirso de Molina, la Villana de Vallecas (Rivad. p. 55):

Es amorado:

Mas que un portuguez.

id. p. 245. Por el Sotano y el Torno:

Si amor nacio en Portugal,

Ia es portugueza Castilla.

id. p.. 209. Fil Vergonzoso en Palacio:

Ha de amar en su conquista

De oidas el Portuguez.

Jorge Ferreira de Vasconcellos, Eufrosina p. 296: o bom portuguez da sua natural constellaçđo apurado no amor.

id., Aulegraphia p. 121: en esta tierra (de Portugal) do todo es locura $y^{\prime}$ fantasia.

id., ibid. p. 38: porim, o amor he portuguez, e quem al disser nato the salve sondar as alturas e navega por fora de todo o bom sentir.

id., Eufrosina p. 294: E por isso ride-vios dos namorados negarcis ser esta a principal inclinaçato portuguezn.

D. Francisco de Portugal, Arte de Galanteria p. 84: Sin ninguna competencia fue siempre Portugal la escuela de la fina galanteria. De aqui aprendieron todas las naciones finczas.

ibid. p. 115: como se entre as capas de baeta de Portugal deixasse ainda de haver alguns que de amores se mantêm.

D. Francisco Manoel de Mello, Epanophoras p. 286: e como nosso natural é entre as mais naçzes conhecido por amoroso.

An die oft citierten Stellen aus Madame de Sévigné und des Cervantes Persiles y Sigismunda brauche ich nicht zu erinnern. 
schon die Überschrift a huma fuala Gonçalvez zeigt, die auf den Familiennamen und nicht, wie gewöhnlich, auf den Rufnamen hinweist - Gonçalves ist der Familienname der von Camoens angesungenen Schönen. Derselbe scheint bedeutungslos und ciner Auslegung unfähig. gewinnt aber Sinn und Bedeutung durch eine ganz leise Ânderung in der Aussprache, durch Schärfung des anlautenden g zu k. lis sei nun, dafs besagte Schönheit sich wirklich Con-salves geschrieben habe - eine Form, die in alten Dokumenten nicht selten vorkommt - es sei, dals der Dichter die Änderung willkürlich und auf eigene Hand vorgenommen hat, mir scheint, man müsse Comsalves lesen, $d . h$. ich nehme an, der Dichter habe clen Namen als einen auslegungsfähigen empfunden und ihn aus diesem Grunde, der Mode gemäls, vielleicht gar, wie meistenteils, auf der Dame ausdrücklichen Wunsch und Befehl, kunstgerecht in sein (ielegenheitsgedicht hineingeheimnifst. Ich denke dabei nicht an das obligate Spiel mit Vornamen wie Luz, Paz, Graça, von dem schon oben die Rede war; auch nicht an das schwierigere mit auf den ersten Blick sinnlosen wie Lianor, Dorotea etc. ${ }^{1}$; ich denke nur an das Spiel mit wirklichen Familiennamen; erinnere z. B. an No. 82, wo der Name Quaresma, und an 88, wo Morais gedeutet wurde, und mache auf zwei Gedichte aufmerksam, in denen etwelche Damen Soares gefeiert wurden. Das eine steht in der Miscellanea des Miguel Leitão (p. 187) und tändelt mit besagtem Namen, den es als Verbalform von soar = „tönen" falst und verwendet.? Das andere ward, so viel ich weifs, noch nie gedruckt. Ich kenne es aus der hand-

1 Verse auf jegliche Lianor mufsten mit dem Verbum liar spielen. Der König Johann II. trug bei den berühmten Hochzeitsfeierlichkeiten des Kronprinzen Affonso als Emblem Stricke = liames de nave mit dem Motto:

estes lido de maneira que jamais pode quebrar quem com elles navegar.

Eine Dorotea besingt J. F. de Vasconcellos (Aulegr. p. 88) in einem Vilancete. Es beginnt:

Dorotea, dor se atea no meu triste coração vendo vossa isençăo.

2 Es heifst dort: .... tornou o musico a cantar por outra toada, com os olhos na dama menor (que dona Elvira Soares se chamava) o seguinte:

Se pelo que de vos soa se passa a vida em pezares, que será por vós soares?

Se soares, e ouvida for essa voz excellente, bem sei eu alguma gente que dará a troco a vida: Nao queirais que a partida se passe toda em pezares com, senhora, ñ̃o soares.

No extremo se mostrarao alegres estas donzellas (zwei Schwestern Soares), da cantiga, assi por nella verem metido o seu nome, como pelo remoque e toada. 
schriftlichen Miscellanea Juromenha (fol. 90), wo es ohne jegliche Angabe über den Autor steht. Fs deutet Soares durch so ares = „nur Wind" und spielt recht anmutig mit dieser Formel." In derselben Weise meine ich nun, dafs Camoens mit dem Namen Gonsalves oder Consalves scherze, den man in com salves = „mit Grülsen“ zerlegen müsse, um die Amphibologie des Liedchens zu verstehen.

\section{Mote.}

- Só ares te daræo vida

Se só nelles esperares: -

- Sim, mas dizem que he perdida

Esperança, posta em ares. -

(ich vermute em so ares.)

\section{[Glosa.]}

Tem me morto hum gentil ar

De hums claros olhos que vi;

Outros ares concebi

De vão cuidar e esperar

Que me tem fóra de mi.

Do que ares só me causárão,

(vielleicht: Do que só ares causárão)

Me queixo ao cego omecida.

Responde: „elles ferem e sárão.

Se sí ares te matárão,

So ares te darăo vida".

Vendo quam pouco mereço,

Cuido que enganar me ordena.

Com esperança do que peço,

So ares me deu por pena,

So ares me dá por preço.

Diz me „sim", se as esperanças

Delles fóra de ti fundares;

Mas se sua grandeza olhares,

Bem fundadas esperanças,

Se só nelles esperares!

Mas tarda o contentamento

E vai ja temiendo arnor

Que não ponha empedimento

Meu pouco merecimento

A ssu liberal valor.

Cegão meus olhos em ver

Que não vem sua luz querida;

Nao lhe basta para a vida

Esperança de viver,

Mas dizem que he perdida;

Perdida, ou tam mal fundada

Que em so ares se sustenta,

F segundo este ar lhe venta,

Asi he caida e alçada,

Asi falta ou se acrecenta.

Empinas me alto, ventura,

Para mór queda me dares;

Dás vida para matares,

Dás me por tore (torre?) segura

Esperança posta em (só) ares. 
„Mit Euren Augen, durch Grüfsen, habt Ihr, Herrin; gefangen dies mein $\mathrm{Herz}^{\prime \prime}$.

Das Original sagt este men coraça Méndes, und diese auffällige Formel bedarf ebenso sehr der Frklärung wie ihr schon behandeltes Gegenstück. Es ist klar, dafs, wie die erste Zeile den Schein erwecken sollte, als sei den räuberischen Augen der besungenen Freundin ein Familienname, oder besser ein scherzender Spitz- und Kosename gegeben worden (die in Portugal fast unentbehrliche alcunha), also auch die letzte Zeile der Art gestaltet sein mufs, dafs es aussieht, als sei auch dem gefangenen Herzen ein Wörtlein beigegeben, das, doppelsinnig, zu gleicher Zeit die ureigenste Figenschaft dieses Herzens nenne, und ihm einen Familiennamen gebe. Als portugiesischer Familienname ist und war Mendes ebenso häufig und ungewöhnlich wie Gonçalves, wie jeglichen Fremden ein Blick in irgend ein Adrefsbuch oder z. B. in die Listen der Hofstaaten der portugiesischen Könige lehren kann (Sousa, Hist. Gen., Provas vol. VI).

Doch was bedeutet es sonst, wo es als Eigenschaftswort oder Adverb auftritt? Míndes oder méndez ist nichts anderes als eine jüngere, heute freilich schon veraltete und den meisten Portugiesen unbekannte Form des älteren mides ', d. h. des lat. mel-ipse; es bedeutet also nichts anderes als "selbst" mesmo (met-ipsimus) und ist in allen mir bekannten Fällen mit "selbsteigen, leibhaftig, in eigener Person" zu übersetzen, da es stets dazu dient, mit grolser Kraft und starkem Nachdruck auf das Substantiv, welches es begleitet, hinzuweisen.2 Camoens will also mit coraçao méndes sagen: gerade so wie Ihr ganz Auge seid, wie Eure Augen das Hervorstechendste an Euch sind, so dafs sic Euren Vatersnamen zu tragen verdienen, so bin ich ganz Herz, d. h. ganz Seele, ganz Gefühl, ganz Hingebung.

Schon ein anderer hatte vor Camoens sein Spiel mit dem Namen Mendes getrieben, und an diesen anderen dachte der Dichter sicherlich, als er sein Liedchen verfafste; an diesen anderen, allbekannten, mochte und sollte sich aber auch Dame Gonsalves erinnern und den für Portugiesen des 16. Jahrhunderts ohne Zweifel überhaupt wenig schwierigen Doppelsinn gleich herausfinden.

Die Mofina Mendes des Gil Vicente (1534 geschrieben) ${ }^{3}$ ist die

1 Für die Betonung méndes sprechen viele Stellen, in denen mendes auf tendes (tenetis) und éndes ( $=$ index) reimt, $z . \mathrm{B}$. in den Autos de Antonio Prestes p. 250 und p. 127. Cfr. Ztschr. VII i12. Für die daneben jedoch zu recht bestehende Betonung medés, wie in den Neu-Ausgaben alter Chroniken und Autos bisweilen gedruckt wird, spricht eine Stelle im Canc. de Res. I 79, wo medes auf tres und mes reimt.

2 Ulysippo p. 20Iv: Dados tomara eu agora aqui de boamente. - E eu primeirinha mendes $=$ "Würfıl hätt' ich jetzt für mein Leben gern hier. Und ich selber, d. i. und ich erst, für meine eigene Person". - Eufros. p. 194: Escovinha mendes! = „Du selbst, Du in Person, bürste mich ab"; etc.

${ }^{3}$ Das Wörterbuch von Moraes verweist unter mendes auf eine andere Posse von Gil Vicente, den Clerigo da Buira. Gewifslich ist das Auto de 
typische Gestalt, in der die bekannte Fabel mit dem Milchtopf personificiert worden war.

Nofina Mendes ist ein übermütiges Bauernweib, das einem reichen Landmann als Hirtin dient. Während ihrer Dienstzeit schlägt diesem jedoch alles fehl, alles milsrät ihm: er sagt daher nicht Nein, als sie ihren Abschied verlangt. Als Lohn giebt er ihr, nach gethaner Abrechnung, bei der er ihr all das Leid vorhält, das ihm durch sie widerfahren, einen Topf voll ÖI, den sie auf dem Markte verkaufen soll. Und sie baut nun, glücklich im Besitz des Öltopfes, kühn ihre Luftschlösser auf, ähnlich wie die Besitzerin des Milch- oder Honigtopfes im Pantschatantra, beim Grafen Lucanor, bei Lafontaine und (ileim; springt tanzend in die Höhe; der Topf fällt und liegt in Scherben zu ihren Füfsen. Dies der Sinn der kleinen Farce. Dals aber Mofina Mendes nicht einfach als Eigenname gefarst werden darf, sondern in seine ursprüngliche Bedeutung als "das Unglück selbst, in Person" " 1 zurückübersetzt werden mufs, beweisen folgende Stellen (Gil Vicente II p. 1 1 2, I1 3, $114,116)$ :

1. - Mofina Mendes quanto ha que vos serve de pastora? -

- Bem trinta annos haverá, ou creio que os faz agora; mas socego não alança; ño sei que maleita a toma. Ella deu o sacco em Roma, e prendeu el rei de França; agora anda com Mafoma e poz o Turco em balança. -

2. Mas crê que andou per hi Mofina Mendes, rapaz. -

3. Que a negra burra ruça, Mofina Mendes deu nella. -

4. Porque mais corre a Mofina vinte vezes que a raposa;

und ganz besonders eine fünfte, die der Bauer nach dem Einsturz aller Luftschlösser spricht:

$$
\begin{aligned}
& \text { 5. Agora posso eu dizer } \\
& \text { e jurar e apostar } \\
& \text { que es Mofina Mendes toda. }
\end{aligned}
$$

Ob Mofina Mendes ein von Gil Vicente selbst erfundener Name ist, oder ob er bereits für die typische Gestalt der „Milchfrau“ existierte,

Mofina Mendes gemeint; denn im vorgenannten Stücke kommt das Wörtchen mendes nicht vor.

I Man denke an Uhlands „Unstern, diesen guten Jungen“, an Chamissos „Pech" und andere ähnliche Gestalten. Auch im 29. Kap. des Conde Lucanor ist der Name der Milchfrau doñn Truhana ein bedeutungsvoller. 
oder allgemeiner für dás personificierte Unglück, das weifs ich nicht, doch glaube ich, die letztere Vermutung sei gerechtfertigt. Irre ich nicht, so giebt es ein altes Sprichwort über Mofina Mindes. Dafs Jorge Ferreira de Vasconcellos sie kennt ', beweist nichts: er kann ebenso gut nur an Gil Vicentes Schöpfung gedacht haben, gerade so wie Camoens that, als er sein im Dienste der Olhos Comsalves stehendes Herz, Coraçao Mendes tạufte.

No. CXXIII. Über die Volkslieder von der spröden Schönen (Menina fermosa - mas despiedosa) s. Sâ de Miranda Anm. 190.

No. CXXVI. Das Thema scheint ein spanisches gewesen zu sein, s. Salvá II p. I9. Daher das mas an Stelle von port. mais.

No. CLII. Fin gewisser Affonso Lobo hat ein Villancico mit der Anfangszeile Nasce a estrella da alva komponiert, s. Catalogo de D. Joăo IV p. 245. S. oben No. I.XII.

No. CLIV-CLXI. Prosabritefe. Da ich bis heute mein Versprechen (Ztschr. IV 609), einige Bemerkungen zu den schwierigen Prosabriefen anderwärts mitzuteilen, nicht erfüllt habe, so stelle ich hier zusammen, was ich für erwähnenswert halte.

CLIV. Das erste Briefchen (154) steht in der That, wie Juromenha behauptet und Storck wiederholt, in der einzigen Quellenhandschrift, d. h. in der Miscellanea J zu Ende einer Anzahl kamonianischer Gedichte. Doch ist diese Anzahl klein. Blatt $54 \mathrm{v}-73 \mathrm{v}$ gehören anderen Dichtern an; auf $73 \mathrm{v}$ folgt das poetische Alphabet (Storck No. XXX), welches Camoens als Verfasser ausdrücklich nennt; daran schliefsen sich fol. $75 \mathrm{v}$ die Trovas que fez um preso d. h. 4 Sonette, die ihm wahrscheinlich gehören; es folgen Novas em resposta d.h. das Absagebriefchen eines Verschmähten, von dem ich oben (No. VIII) gesprochen; dann folyt ein Sonett von Diogo Bernardes (Flores do Lima 3 Dos olhos) und nun ein Sonett von Camoens Novos casos de amor, abermals ohne Nennung seines Namens, und darauf der Brief. Dieser hat keine andere Überschrift als Carta de amores, a modo de piliz̧am. Nachfolgen zwei anonyme Gedichte und hinterher Carta de L. de Camois a hum amiguo, Storcks No. CI.VI. Der I.eser urteile, ob man angesichts dieser Lage ein Recht hat, das kurze launige Briefchen dem Sänger der Lusiaden zuzuschreiben. Die Schlulsabbreviaturen, welche Juromenha $E R . M^{c t}$ liest und die Storck als eine unterbrochene d. h. nur angedeutete Unterschrift auffafst, bestehen im Ms. aus nichts als den deutlichen Buchstaben $R . M$. Statt vossa perfeiça setze man essa, denn also steht geschrieben.

CLV. Zum „Schreiben eines Freundes, und Camoens' Antwort", dessen einzige Quelle abermals die Miscellanea J ist (fol.86v), mufs ich bemerken, dafs ich, wie Storck, an ihrer Echtheit zweifle. Nichts spricht dafür, dafs Camoens einer der Briefsteller sei, es sei denn man wolle folgenden Sachverhalt für beweisfähig halten:

1 Aulegraphia p. 52: fermosura com "a gloria dana mais do que aproveita, e as mais das vezes lhe corre per davante mofina. mendez. 
In der Handschrift folgt auf einen wirklich dem Dichter angehörigen Brief (No. CLVI-CL.VIII), welcher fol. $79 v--85 v$ einnimmt, erstens ein anderes Prosastück, ein Fragebrief des Grafen von Alcoutim an A. de M., und zweitens die entsprechende Antwort, fol. 85v-86; drittens ein ganz gleichartiges Werk, betitelt Carta de preguntas, abermals mit der entsprechenden Entgegnung (Reposta). Diese letzteren beiden sind es nun, die Juromenha dem Dichter zugeschrieben hat, einzig und allein darum, weil sie herrenlos waren und im Manuskripte in der Nähe eines kamonianischen Erzeugnisses Platz fanden. Trüge die zwischen diesem und jenen stehende Korrespondenz nicht den Namen des Grafen von Alcoutim, so würde wohl auch sie in die Werke des Dichters Aufnahme gefunden haben. Liegt es aber nicht näher, den zweiten Fragebrief dem ersten Frager, dem Conde de Alcoutim, und den zweiten Antwortsbrief dem ersten Antwortgeber, A. de M., zuzuschreiben? An Klarheit übertrifft der erste den zweiten in etwas, an Interesse steht er ihm nicht nach. Der eigentümlich gekünstelte, geschraubte, verzwickte, absichtlich schwer zu verstehende, mit Allusionen gespickte unpersönliche Prosastil damaliger Schriftstellerbriefe macht es jedoch ganz unmöglich aus der Schreibweise auf den Briefsteller schliefsen zu wollen.l Was ich von diesem Genre kenne:

\section{1 [fol. 85v] Do Concle de Alcoutim a A. de M.}

Estando em conversação, descansando da caça em hũa aldeia deste termo a que chamão as Cortes, passou um soldado da India que disse haver escapado da nao de Fernão de Mendonça; ao qual eu e o duque meu senhor perguntános mil cousas de seu naufragio, a que elle satisfez como ta (testemunha) de vista. E querendo saber mais se determinava tornar á India pois de tal escapara, respondeo que ,per de baixo da augua, não havendo outro caminho", porque o medo que ja perdera lhe dava animo pera acometer tudo. E porque me pareceu grande o spirito deste soldado e mór a força da India que assi chana e come homens, e igual a ambos a confiança em que o costume pỡ aos que navegão, haverei por grande mimo d'essa mão, que tudo pode, apontarme o senhor. (sic)

$\mathrm{Na}$ primeira o duque c eu veremos que calidade tem a India na voz comurr, joisis obriga a tanto, c que dá confiança a homens tam desenganados de perigos allocios para não temerem os proprios; e que força he a do costume yue isto fnz minis facil. F. entretanto veremos se são milhores os porcos d'nqui que os de Alem-Tejo.

Reposta.

Devo tanto ao gosto com que V.S. scmpre se serviu de mim que tudo o termo, fora de mandar-me como criado, me faz sospeita de ter minha esperança morta; porque so este nome he $o$ aceno a que a obediencia mais acode e milhor conhece.

Quanto ao que V.S. me manda que responda, farei com mor gosto que suficiencia, por ser materia em que hei de falar por emformaçðes. - E vindo á pregunta, ocasionada da reposta do soldado, direi o que eu vi praticar ao[s] homens antigos da India e muito versado[s] nella; e dahi farei consequencia ao erro de quem a busca a seguc (d.i. e segue), que he a confiança nacida do costume, com que tantos a buscão. Quanto á India sempre ouvi dizer que era sepultura de homens nobres, praça de cavalleiros, feira de feitos illustres, força de poder real $\mathrm{cm}$ fronteira de tantos imigos; pelo que nella ha bũa medida igual de esforço (de) para desiguais em sangue. $\mathbf{E}$ os que disto fazem emprego, primciro devem do que tenhão; porque o que prometem 
die Camoens zugeschriebenen Episteln, die des Grafen von Alcoutim, die von Soropita, von Jorge Ferreira de Vasconcellos und von D. Francisco de Portugal gleichen sich wie ein krauses schwarzes Haar dem anderen. 1

Was den Stoff der von Storck übersetzten Korrespondenz betriff, so erinnere ich an die Frage- und Antwortspiele, mit denen die adeligen Herren, welche um Sâ de Miranda und seinen Schwager Manoel Machado de Azevedo geschaart waren, sich Abends unterhielten (Braga, Quinhentistas p. $\mathbf{I}_{4}$ ).

Der Text bedarf der Nachbesserung J.V p. 24I, I 8 creio für creia. - I9 dovido für decido. Diese Lesart klärt den Sinn auf: Dieselben Fragen sind schon einmal gestellt und beantwortet worden, zur Zufrierlenheit des Schreibers, doch nicht zur Zufriedenheit anderer Freunde, die daher noch einmal dieselbe Litanei singen. Deswegen entschuldigt er sich und fihrt fort: digo que dovido por outrem (nem me pejara de confessar, por ser de v. m. reposta, que eu era o que dovidava etc.). Damit vergleiche man auch im Antwortschreiben den Satz teve pejo em responder a estas duvidas (p. 242, I I), und in seiner Schlufsformel estas opinizes com que as duvidas respondo (p. 244,3$).^{2}$ - 24 avisando-me für avisando. p. 242 Reposta für Resposta. - 8 Die nach forma stehenden Buchstaben sind $\mathrm{Co}_{\mathrm{t}} \mathrm{h}$ li belua: einen Sinn vermag ich darin nicht zu entdecken. Unwillkürlich aber fiel mir die Formel $x . p . t . o=x i s-$ $\hat{p} \hat{\imath}-t \hat{\imath}-\hat{v}$ ein, welche der Portugiese sonderbarerweise scherzhaft dazu verwendet, um etwas ganz Exquisites zu bezeichnen, z. B. uma fita,

a hum hé o que ha de vir a lograr depois da vida de muitos. Por onde tenho averiguado que vende caro o que manda, ou o troca com vantaigem, pois, levando homen; e dinheiro, manda pedra e barro, no que bem se mostra quantos milhores são os empregos que os retornos. E se V. S. pregunta quem dá animo a homens desenganados para seguir tal partido (deixando os perigos da passagem que são para temer tanto), digo que he a enganosa confiança que aos homens dá estes infortunios, sendo esta esperencia a que dá mais que temer; porque ainda que a confiança nas cousas ordinarias he suave meio, nas que o năo são, he bem fraco remedio. Donde os Egyptios a pintarăo cega, ou porque se engana no mais do que espera, ou porque está ás escuras do que dezia. E ajuda-se esta confiança da com que se navega hum mar tanto mais indomito quanto mais tratado. Por onde entendo que o primeiro engano deste soldado não he não te[me]r o perigo que o costume dos outros lhe faz facil cometer, mas o não conhecél-o, porque antão ou o cometerá como tal, ou se arriscará menos enganado. $E$ pois elle tem tanto de que se engane,| siga se quizer seu erro; que eu fico com este desengano que a India deve ser buscada ou dos venturosos ou dos desemparados, porque aquelles tudo vencem, e estes nada temem.

E pois V.S. me falla em porcos, será para mim mui grande, se o eu não vir este Natal, verem me elles a mim; e entăo me terei para algũa cousa quando for mandado em muitas do serviço de V.S. a quem etc.

1 Den von Joåo Lopez Leitão verfafsten Brief in Camoens Manier, von dem Storck auf p. 372 spricht, kenne ich nicht.

2 Demgemäls ist zu übersetzen (CLV 3I) ,dafs ich tür einen Anderen zweifle". - Zu Anfang des Bricfes (Z. 5) würde ich respondéra für responderá lesen und also im Deutschen sagen "womit Sie meine weitschweifigen Fragen beantwortet haben". 
um vestido $x i s-p \hat{i}-t i-0$. - vinlagem de] vantagem do. - 9 para por paradoxos] por paradoxos. - 12 de] do. - 19 injuria, aquelle] injuria aquelle, - 21 seja formalmente hum pesar, desgosto, e affronta] seja hum pesar, o desgosto e a affronta. Storcks Nachbesserung zu dieser Stelle ist somit nicht mehr nötig. - 23 o que magoarem] ao que magoar. - 28 dinheiro que honra] honra que dinheiro. - p. 243,6 trabalhar-se] trabalhosa (?). - I I não-no podem] nao pode. - I 5 lempo em que ella se conserva] tempo, e aquella se conserva. Storck hat richtig erkannt, dafs etwas falsch ist; sein Besserungsversuch ist nunmehr unnütz. - 23 algum que á esperança chame engano] alguns q. $a$ e. chamem eng. - 24 isso nao tira a verdade de quem sabe situal-a] isto nao terí a verdade de $q$. situlal-a. - 25 mancipon] cmancipou; esperiença] esperança. - 26 chamaria] chamarei. - 28 faz] fez. 29 hinter desesperaçao folgt noch eine Phrase que é oposta da divina $M^{a}$. (misericordia? Maria?). Juromenha liefs die Stelle fort, aus Furcht sie ungenügend zu interpretieren. - 30 por tal meio] por tal termo. - 34 a hĩa] a hum. - 35 tanto ha] tanto.

No. CLVI. Dieser Prosabrief - von dem die als No. 157 und I58 mitgeteilten Fragmente thatsächlich nur Bruchteile sind - ist aus inneren und äufseren Gründen wohl echt: als innerer Grund gilt vor allem, dafs ein kamonianisches Gedichtchen darin vorkommt (das vom flügellahmen Rebhuhn), welches damals wohl kaum allgemein bekannt, sondern nur dem Verfasser und demjenigen, dem es gewidmet war, vertraut sein konnte. Die äufseren Gründe sind, dafs der Brief seit 1598 dem Dichter zugeschrieben wird, dafs auch die Niscellanea Juromenha ihn Carta de L. de Camois nennt, und dafs ein in Fvora ruhendes Manuskript ( $\frac{\text { CXIV }}{1-39}$ fol. 167) - von dem ich persönlich leider noch nicht habe Einsicht nehmen können - das gleiche thut. Die Handschrift, nach welcher Estevam Lopes zuerst den Brief abdruckte, scheint jedoch sehr verderbt gewesen zu sein: an dem von ihm überlieferten Texte haben spätere Herausgeber wenig und ungenügend nachgebessert; er befriedigt keineswegs. Mit Hilfe des Ms. J läfst sich zum Glück an vielen Stellen die echte und rechte I.esart herstellen. An einzelnen Orten ist jedoch auch sie mangelhaft. Da nun Juromenha, als er in fünften Bande seiner grofsen Camoensausgabe die Prosastücke veröff ntlichte, vergessen hat sein kostbares. Manuskript zu Rate zu ziehen - obwohl er seinen Lesern davon als von einem wesentlichen Hilfsmaterial zur Reinigung des Briefes bereits im ersten Bande (l 1 1 7 ) gesprochen hatte, so bleibt es mir vorbehalten seine Lesarten hier zum ersten Male zusammenzutragen. Da ich aber verschiedene Bemerkungen an dieselbe knüpfen und gleichzeitig die deutsche Übersetzung ins Auge fassen möchte, so ziehe ich es vor das Original, so wie es in der neuen Gestalt aussehen mufs, abzudrucken und meinè Frklärungen nebenhergehen zu lassen. Die Abweichungen von dem bisher bekannten Texte sind durch den Druck hervorgehoben; die Interpunktion und das typographische 
Arrangement, d. h. das Hervorheben der Citate, Sprichwörter etc. 1 stammt von mir; die Orthographie folgt der des Manuskripts, die nur in kleinen unwesentlichen Zügen geregelt, aber nicht modernisiert ward. Besonders erwähnenswert ist, dafs Storcks aus einer gelegentlichen Bemerkung Juromenhas (I 17) geschöpfte Vermutung über die Zusammengehörigkeit der drei Brieffragmente (156. I 57 . 158), ja sogar über die Stelle, wo das in portugiesischen Ausgaben bisher niemals aufgenommone Fragment No. I57 einzufügen ist, durchaus das Richtige getroffen hat.

Ein sonderbares Machwerk ist dieser Brief freilich. Einem modernen Gefühlsergusse, wie man ihn Freunden gegenüber vorzunehmen pflegt, ist er überaus unähnlich. Ein aus Sprichwörtern, Citaten, eigenen und fremden Gedichten, fremden längst bekannten Gedanken, die man nur in neuerfundene Worte gekleidet hat, künstlich und mühsam arrangiertes und zusammengeflicktes Zwitterding, das mit einem Auge den Specialfreund anlächelt, der jegliche Allusion verstehen mufste, und mit dem anderen das Publikum auslacht, das sich den Kopf dran zerbrechen soll! Besonders zu diesem Briefe bilden die hochinteressanten Cartas des D. Francisco de Portugal ein aufklärendes Seitenstück. ${ }^{2}$ Von der Eigenart des Genre scheint es mir unmöglich durch eine Übersetzung ein treues Abbild zu geben.

Überall einen Zusammenhang der Gedanken herausfinden zu wollen, wäre ein vergebliches Bemühen. Was Storck z. B. als No. 158 bietet, ist, in meinen Augen, welche das Ms. J geöffnet habt, eine Serie feiner, aber loser, durchaus zusammenhangslos dastehender Sentenzen. Es sind Gedankenspähne, die der Dichter heute und gestern auf lose Blättchen niederschricb und dic cr hernach einem Herzensfreunde als sprechendstes Zeugnis für seine jüngsten Stimmungen sandte.

\section{Misceillanea JURomenha.}

No. III.

[fol. 79v] Carta de L. de Camois a hum amiguo.

Esta vai com a candeia na mão morrer $n a^{3}$ de v. m.; e se d'ahi passar, seja em cinza, porque năo quero que do meu pouco comam nuitos. É se todavia quiserem ${ }^{4}$ meter mais mão $a^{5}$ escudela, mande-lhe lavar o nome, e valha sem cunhos. ${ }^{6}$

1 Überall da wo mein Nachdruck einen Trennungsstrich aufwcist, finclet sich im Manuskripte ein durch einen kleinen weifsen Zwischenraum und durch einen Schnörkel gekennzeichneter Abschnitt.

2 Sind sie reine Cartas de giröes?

3 Die Drucke lesen nas. - Alle Lesarten, bei denen ich nicht ausdrücklich das Gegenteil bemerke, sind sämtlichen Camoensausgaben gemein.

4 quizer. s na.

- Diese Redeweise hat Soropita in einem seincr Briefe nachgeahnit, zum Teil wörtlich wiederholt (XV 8 esta, senao morrer nessas mäs, valha sem cunhos). Etwas Besonderes kann ich auch nicht an den Eingangsphrasen 
La mar en medio y tierras he dexado

Mas $^{2}$ $y^{1}$ quanto bien, cuitado, yo tenia..

quan vano imaginar, quan claro engaño es dar-me yo a entender que con partir-me de mi se ha de partir un mal tamaño.

Quam mal está no caso ${ }^{3}$ quem cuida que mudançat de lugar

Muda a dor do sentimento ${ }^{5}$;

e senão, diga-o

quien dixo que la ausencia causa olvido. ${ }^{6}$

Porque, emfim,

la tierra fica

y lo mas a alma acompanha.?

Ao alvo d'estes cuidados jogam, ha muito ${ }^{8}$, meus pensamentos á barreira, tendo-me já, pelo costume, tam contente de triste que triste me far $a^{9}$ ser contente,

wittern: ward der Brief in Ceuta geschrieben, so erlaubt die Jugend des Dichters, der an einen hohen Herrn schreibt, darin einfache Versicherungen einer, freilich wenig glaubwürdigen, Bescheidenheit zu erkennen.

1 a. Weder das cine, noch das andere ist richtig. De, wie Garcilaso schreibt, ist an Stelle von $a$ und $y$ zu setzen.

2 Dies mas fehlt in allen Drucken. In der Handschrift steht es nicht cingerückt, wie hier, sondern unnittelbar vor quan. Nur ein ganz kleiner weifser Raum, welcher die ersten beiden Elfsilbler von den letzten dreien trennt, macht bemerkbar, dafs es sich um zwei Citate und nicht um eines handelt.

3 Storck übersetzt unrichtig: „Wie schlimm befindet sich in dem Fallc, wer da vermeint ..." Estar no caso heifst = au fait sein, cine Sache recht verstehen. Man mufs also übersetzen: „Wie täuscht sich, oder wie fehl geht, wer davermeint ..."

1 a $m$. de $l$.

5 Diese Sentenz klingt thatsächlich wie ein Vers irgend eines Poeten der ,.cschola velha". Möglicherweisc ist sie jedoch nur eine von Camoens herrührende Formulierung des Sprichwortes quem terra muda, muda ventura.

- Genau so, (dixo für dice), citiert dieselbe Zeile auch D. Francisco de Portugal, Carta p. 45. Sie war geflügeltc's Wort geworden und kehrt oft in den IVerken der Zeitgenossen wieder. Rodriguez Lobo schliefst z. B. eine seiner Elegien damit ab (p. 170 der Obras).

' Einige Ausgaben schreiben queda statt fica; einige en la tierra statt la tierra; alle e o mais für y lo mas: d. h. sämtliche mischen portugiesische Worte mit spanischen. - . Der Satz ist ohne jeden $Z$ weifel verderbt aus

$$
\text { ca fica o haver na terra, }
$$

Sie stammen also, wie die nächstfolgenden drei Citate, aus Christovam Falcãos reizendem Idyll (Strophe 84; ed. Braga p. II), das Camoens aller Wahrscheinlichkcit nach kurz vor dem Nieclerschreiben seines Briefes mit grofsem Genusse gelesen hatte; denn, abgesehen von vier wortgetreu wiederholten Stellen daraus, benutzt er noch viele von Crisfal ausgesprochene schwermütige Gedanken. Ja, die ganze pcssimistische - wahre oder unwahre? - Stimmung, die aus unscrem Briefe spricht, scheint ein Nachklang dieser Lektüre. Wahre Trauer spricht ihre eigene Sprache und borgt sich nicht Gedankenflicken bei Hans und Kunz.

' Fehlt in allen Drucken.

9 faria. 


\section{que o longo uso dos annos ${ }^{1}$}

se converte em natureza

pois

o que hé pera mor mal,

tenho eu pera mor bem,

aindaque pera viver no mundo me debruo de outro panno, por não ficar ${ }^{2}$ coruja entre pardais, fazendo-me um pera ser outro, sendo outro pera $\operatorname{ser}^{3}$ um. Mas ainda a dôr desemulada dará seu fruito', que a tristeza, no coração hé como a traça no pano.
E por tam triste me tenho, que se sentisse alegria, de triste não viveria; Porque a tal sorte vim que não vejo bem algum em quanto vejo; que s não nasceu para mim, e por não sentir nenhum, nenhum desejo.

Porque cousas impossiveis, hé melhor esquecel-as que desejal-as, e por isso

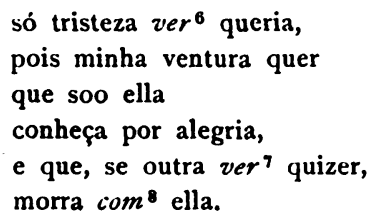

Pouco sabe $d e^{9}$ tristeza quem, sem remedio para ella, diz ao triste que se alegre; pois não vé que alheios contentamentos, av ${ }^{10}$ coração descontente, não lhe remediando o que sente, lhe dobram o que padece.

Vós, se vem á mão ${ }^{11}$, esperareis ${ }^{12}$ de mim palavrinhas joeiradas, enfor-

' porque. Doch ist que die echte Lesart, wie Crisfal sie bietet. Auch ist danos für annos kaum mehr als Schreibfehler irgend eines Kopisten.

2 parecer.

3 Das Ms. schreibt, wohl fälschlich, beide Male parece'r für pera ser.

4 Unbedingt ist auch in diesen Worten eine entweder von den $\Lambda \mathrm{b}$ schreibern entstellte, oder von Camoens ungenau citierte Stclle aus Crisfal zu erkennen. Sie heirst:

In den Drucken fehlt anda.

Anda a dôr desimuladu mas ella darí seu fruito (Str. 43).

s Ms. e. 6 vos.

7 fehlt in einigen Ausgaben; nicht in ed. 1629, 1632, 1651 und 1666.

spor. 9 da. 10 a hum.

1 Die Phrase se vem a $m \tilde{a} v$ kommt noch einnal vor in No. CLVIII Z. 89. - Storck übersetzt das erste Mal ,wenn Euch (dieser Bricf) zu Händen kommt", und das zweite Mal "wenn (sie ihm) in die Hände fallen" d. h. er übersetzt wörtlich, das fehlende Subjekt crgänzend. Se vem $d m \tilde{x}_{o}$ ist aber eine Redensart und bedeutet: wenn der $Z$ ufall es so will, wenn es sich so macht, wenn die Gelegenheit günstig ist (cfr. Eufrosina p. 230).

12 Einige Ausgaben schreiben esperais; nicht so die vier oben (7) genannten. 
cadas de bons propositos'. Pois, desenganai-vos, que dispois que professei tristeza, nunca mais pude ${ }^{3}$ jogar a outro fito. E porque não digais que não sou gente fora $d e^{4}$ meu bairro, vedes, vai hũa volta feita a este mote, que escolhi na manada dos engeitados; e cuido que não he tam dedo queimado que não seja dos que el-rei mandou chamar. $E^{\text {s }}$ falla assi

\section{Mote.}

Não quero, não quero

$x i b a_{0}^{6}$ amarello.

\section{Volta.}

Se de negro fôr, tam bem me parece quanto me aborrece toda $a^{7}$ alegre côr. Côr que mostra dôr quero, e não quero xibao amarello.

Parece-vos que se póde dizer mais? Nav me respondeis $a$ isto: ${ }^{8}$ quem gabará a noiva? ${ }^{9}$ porque assentai 10 que foi ${ }^{11}$ comendo e fazendo ou assoprando, que não he tam piquena habelidade. E porque vos năo pareça que foi mais acertar que querel-o fazer, vedes vai outro ${ }^{12}$ do mesmo jaez, com tanto que se não vá a pasmar:

\section{Mote.}

Perdigão perdeu a pena; năo ha mal que the nåo venha. ${ }^{13}$

\section{Volta.}

Èm hum mal outro começa, que nunca vem só nenhum; e o triste que tem hum, a sofrer outro se ofreça! e só pelo ver 11 conhoca que basta hum só que tenha para que outro the venha.

${ }^{1}$ propositos; hicr wohl eher „Vorsälze“ als „Ratschläge“. Der Übersetzer wählte den letzteren Ausdruck, um ihn mit Zeile 104 in Einklang zu bringen.

${ }^{3}$ soubque. ido. 5 o qual. 6 jubdo.

7 fehlt; nicht so in ed. 1629 etc.

8 nao me respondais.

- Quem gabará a noiva ist ein Sprichwort, das in all den Fällen vorgebracht wird, wo wir mit einem bekannten Wörtchen über „Eigenlob" bei der Hand wären. Cfr. Eufrosina p. 103 u. 231; Ulys. passim.

10 Mas assentui que .... ,prägts Euch recht ein, dafs ..." gehört auch zu den durch vielfache Benutzung recht abgebrauchten Briefstilphrasen (Ulys. p. 2 10).

${ }_{11}^{11}$ fui. 12 outra.

13 Perdiga perdeu a penna ist ein Sprichwort und kcineswegs ein von Camoens erfundenes Motto (s. Bento Pereira).

" ter; nicht so in ed. 1629 etc. 
Que graça será esperardes de mim preposito ${ }^{1}$ em cousas que o ndo tem para comigo; pois, aindaque queira, não posso o que quero; que hum sentido remontado de năo pôr pé em ramo verde, ${ }^{2}$ [tudo lhe succede assi] ${ }^{3}$; e cada hum acode ao que the mais doi,' e mais eu, que ${ }^{5}$

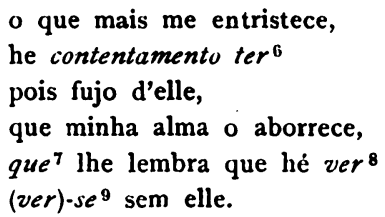

Pois ${ }^{10}$ ja sabeis que magoa he „vêl-o-has, e não-no paparás"; "11 $e^{12}$ por fugir d'estes inconvenientes;
toda a cousa descontente
contentar-me a mim ${ }^{13}$ convinha,
de meu gosto;
que o mal de que sou doente,
sua mais certa mezinha
he desgosto.

Já ouvirieis dizer: „mouro o (sic) que não podes haver, dá-o pela tua alma"." $O$ mal sem remedio, o mais certo remedio ${ }^{15}$ que tem, he „fazer da necessidade virtude" 16; quanto mais
se tudo tam pouco dura,
como o passado prazer. ${ }^{17}$

Pois ${ }^{18}$ emfim:

1 prepositos em cousas que us nao tem. - In ed. 1632 steht cousa. Storcks Übersetzung (s. vorherige Seite Anm. 1) scheint mir nicht das Rechte zu treffen. proposito oder propositos bedeutet hier "à propos", gut passende, schlagende Witzeinfälle. Ich würde übersetzen: „Es ist zum Lachen, dafs Ihr verlangen könntet, ich solle Vernunft reden über eine Sache, die für mich keine hat".

Sprichwort.

3 Das Eingeklammerte fehlt im Ms.

+ Das heifst nicht: "Jeder eilt dem $<$ u Hilfe, der ihn am meisten dauert", sondern ,jeder greift da $z u$, hilft da, an der Stelle, wo es ihn am meisten schmerzt", i. e. wefs das Herz voll ist, defs läuft der Nund über.

s, So thu' a uch ich, denn ..." Storck hat richtig vcrmutel, in den Worten o que mais bis sem elle stecke eine zertrümmerte Copla. Dals dem so sei, bezeugt das Ms.

${ }^{6}$ ter contentamento. ${ }^{7}$ porque; ed. 1632 hat que.

${ }^{8}$ u. ${ }^{9}$ que he virtude viver sem elle. - ed. 1632 de viver.

10 Que; 1632 porque. 11 Sprichwort. 12 fehlt. 13 só.

" Das Sprichwort lautet Mouro que não pódes haver, forra-o, pela tua alma (Nunez fol. 73) und bedeutet man solle sich nicht um Unerreichbares bemühen und nicht um Verlorenes trauern. Man mufs übersetzen: „Einen Mohren, den du nicht haben kannst, gieb ihn frei, bei Deiner Seele". Dic Variante o que nao podés haver, dai-o pela vossa alma (Mello, Cartas familiares p. 348) ist moderner.

15 fehlt. 16 Sprichwort.

17 Ich vermute, die Worte se bis prazer seien ein Vers.

17 Porque. 
allegados son iguales

los que viven por sus manos

i los ricos. 1

A este preposito, pouco mais ou menos, se fizeram hũas voltas a hum mote de enchemão2 que diz por sua arte, zombando, mais que de siso ${ }^{3}$, cuusa pur que me derreto' (que toda a galanteria hé tiral-a d'onde se não espera); $e^{5}$ crede que tem mais que roer [do que hum] ${ }^{6}$ praguento. Por isso ${ }^{7}$

Recuerde el alma dormida 8

e mande escumar o entendimento, porque ${ }^{9}$ d'outra maneira

de fuera dormiredes, pastorico. 10

1 fehlt im Ms. Doch bilden die drei Worte die notwendige Ergänzung des sonst unverständlichen Citates. Selbiges stammt aus Jorgc Manriques vielbenutzten, viclcitierten, parodierten, glossierten und nachgeahmten Coplas (Leincke II p. 172 Z. 3-5), an welche, wie Storck richtig zu Z. 39 bemerkt, die von Camoens diesem Briefe eingestreuten Stegreifverschen nicht nur in formeller Hinsicht, sondern auch dem Inhalt nach erinnern. Ihre Bedeutung ist eine ganz andere als der Übersetzer vermutet, nämlich: „A ngekommen (nänlich an Ziele ihrer Lebenspilgerschaft), sind reich und arm einander gleich.

2 Mote d'enchemao übersetzt Storck in Übereinstinunung mit den Wörterbüchern mit "ein vortreffliches Motto". Ich glaube, dafs es gerade das Gegenteil bedeutet ,ein nichtssagendes Motto", wie es man zu einer Hand voll guter als $Z$ ugabe beigiebt. Sonst verstehe ich die Bemerkung nicht ,es enthalte, obwohl in scherzender Form, ganz unerwarteten Ernst, es stecke mehr in dem Motto als es den Anschein habe". Ich mufs gestehen, dafs ich den versteckten tiefen Ernst und die bittere Satyre nicht herausfinde, so viel ich auch am Motto und an den Voltas "nage"; vor allem kann ich denjenigen Sinn, der doch drin stecken murs, dafs nämlich alle Menschen Brüder seien, und dafs der Tod alles gleich mache, durchaus nicht darin entdecken.

3 mais que nato de siso.

- = „eine Manier, in die ich schier verliebt bin“. - Fehlt in den Drucken.

so qual. Das o qual bezicht sich nicht, wie Storck annimmt, auf siso, sondern auf mote. Ich verstehe:, ein Motto,.... an dem es mehr zu nagen giebt als an einem boshaften und offen satyrischen".

"fehlen im Ms.

7 Ich würde sagen: Deshalb

Wach' auf, du verschlafne secle

Und lafs den Verstand abschäumen; denn sonst

Wirst $d u$ heute draufsen schlafen,

Lieber Hirt!

Die Intention des Dichters und der Zusammenhang der einzelnen Glieder wird so klarer ersichtlich als bei Storck.

${ }^{8}$ Braga, Hist. de Cam. II p. 572 meint, Camoens spiele hier auf eine von ihm selbst herrührende satyrische Glosse von Recuerde el almu adormida an, welche der Cancioneiro de L. Franco, doch ohne jegliche Angabe über ihren Verfasser aulbewahrt hat. - Das glaube ich nicht. Die Glosse irgend eines dichterisch begabten Indienfahrers, welche der Leser in Bragas Werke I p. 424 findet, ist wohl kaum von Camoens. Der Prosabrief aber ward aller Wahrscheinlichkeit nach geschrieben während der Dichter noch in intimen Beziehungen zum portugiesischen Hofe stand, ich meine zwischen 1542 und 50: eine Anspielung auf ein in Indien also nach 1553 verfafstes Werk kann cr also nicht enthalten. - Das vorhergegangene Citat aus den "Coplas" fuhrte naturgemäls zur Benutzung auch der sprichwörtlichen Anfangszeile derselben.

${ }^{9}$ que. $10 \mathrm{Im}$ Ms. verderbt. 
E o meu, senhor, he ${ }^{1}$

\section{Mote.}

Dava-lhe o vento no chapeirăo

quer [lhe] dé, quer não."

Volta.

Ben o póde revolver

que vento ${ }^{3}$ năo traz mais fruito;

e mais vento he sentir muito

o que emfim fim ha de ter.

$O$ milhor he melhor ser

que o vento no chapeirão,

quer lhe dê, quer năo.

Hốa cousa sabei de mim, que queria antes o bem do mal que o mal do bem; que ${ }^{s}$ muito mais se sente o porvir que o passado, e a morte, até matar, mata. Năo sei se sereis marca de voar tam alto; porque para tomar a palha a esta materia são necessarias azas de nebri. Mas vós sois homem de prol, e eu salvo-me na conta ${ }^{6}$ em que vos tenho. A que de mim vos torno a dar $^{7}$ hé que
Esperança me despede,
tristeza não me falece.
E todo o mais aborregion,
ja que mais não mereceu
minha estrella:
$E s^{9}$ tristeza conheço,
poisque para mim nasceu
e eu pera ella. ${ }^{10}$

No mundo não se tem por bou a surte"l senăo [de] quem tem por boa a que tem. E d'aqui vem contentarme de triste. Mas olhai de que maneira :

1 E o men senhor(?) diz assi.

2 Auch dies Thema ist nichts als ein Sprichwort (Bento, Pereira), dessen Ursprung und feinerer Sinn mir noch verborgen ist. Mello, Cartas familiares p. 347 sagt: sí sey que estou ja muito peor que o chapeiralo de D. André em que dava o vento, quer lhe dề quer nao.

3 o vento. "Hier ist ein kleiner weifser Raum. "porque.

i e desculpa-me a conta.

I E a que de mi vos sei dar.

8 me aborrece. 9 Só a.

10 Die Lesart der Drucke war sichtlich verderbt. Der deutsche Übersetzer suchte mit Recht eine sechszeilige Manrique-Copla herauszuschälen, wie solche in diesem Briefe achtfach, und in seiner zweiten Hälfte (CLVIII) fünffach vorkommen. Im Gedanken an das "Trübsinn" überschricbene Liedchen (Z. 39-47) glaubte er cine dreizcilige Einleitung ( $x$ a a) und cine Copla vor sich zu haben, in welcher Zeile 2 verloren gegangen sei. Er ergänzt Que sem fim dores padeço. - Das Ms. aher stellt in einfacher und durchaus genügender Weise eine fehlerlose Copla her, der freilich nur zwei Einleitungszeilen vorangehen.

11 nao tem boa sorte senao quem. 
Vivo assi an reves, tomando por certa vida certa morte, com que folgo, êmque me pez'' pois minha sorte he servida de tal sorte. ${ }^{2}$

Hũa cousa sabei que o mal, ainda que ás vezes o vejais louvar, não ha quem o louve com aboca que o não tache com o coraçăo. E tornando a terra ${ }^{3}$ :

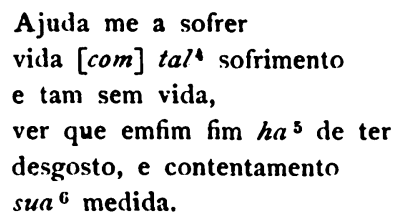

Asentai ${ }^{7}$ que não săo tam maos $^{8}$ conceitos $^{9}$ de enforcados para os que estão com o baraço na garganta cuidar que o bem e o mal, aindaque diferentes $^{10}$ na vida. săo conformes na morte;

Que nao ha tam alta sorte nem ventura tåo subida ou desestrada, a quem um sopro da morte 11 não sopre o fogo da vida e torne em nada. 12

A seu fim toda a cousa vai ${ }^{13}$ correndo, nem ha cousa que o tempo năo consuma nem vida que de si tanto presuma que se nåo veja nada, em se vendo.

Que o mais certo que temos he nada téremos' 14 certo ca na terra; porque por seus 15 não nacemos, se o seu nos dá incerto, nada erra."

1 Scheint mir nicht gut verständlich. Der Dichter sagt: „ich lebe so widersinnig, dals ich im Tode Leben erblicke und daran Gefallen finde, so sehr es mich auch bekümmert" - êmquz me pez. ${ }^{2}$ Abschnitt. 3 fehlt.

- tan sem: scheint mir eine unmögliche Lesart. 5 hao.

6 sem. Ed. $163^{2}$ liest hüa medida und so dürften vielleicht auch die Buchstaben gedeutet werden, die ich als sua verstehe.

7 Attentai. Cfr. S. 435 Anm. 10. 8 maos. 9 confeitos(!).

10 ainda que sejam $d$.

11 o assopro. Ed. 1632 sagt a quem nao assopre a morte.

12 fehlt. Storck suchte die unvollständige Strophe zu ergänzen durch tao desejada : lauter feine und gute Conjecturen, die aber angesichts der Wirklichkeit weichen müssen. - Die drei Versgruppen sind im Ms. deutlich von einander geschieden. 13 todas cousas vão. " nao termos nada.

15 pois para seus. - Im Ms. ward seos zu ceos verändert, wie in der folgenden Zeile seo zu ceo. 10 Abschnitt. 
Quero-vos dar conta de hum soneto sem penas (?)', que se fez a hum certo recontro que se teve com este destroidor de bons propositos; e não se acabou porque se teve por mal empregada a obra, cujo teor he o seguinte:

Forçou-me Amor bum dia que jogasse; deu as cartas, e $[\mathrm{az}]^{2}$ de ouros levantou, e, sem respeitar mão, logo triumphou cuidando que o metal $\mathrm{mo}^{3}$ enganasse. Dizendo, pois triumphou, que triumphasse A hua sota de ouros que jogou, Eu tambem 4 por burlar quem me burlou tres paos joguei e disse que ganhasse."

Principes de condição, indaque ${ }^{6}$ o sejam de sangue, são mais cnfadonhos que a pobrcza, e fazem com suas fidalsuias com que lhe carem a de seus aq'ós?, onde não ha trigo tam limpo ${ }^{7}$ que não tenha algũa crvilhaca. $E^{9}$ ja sabeis que basta um frade roim para dar que falar $d e^{10}$ um convento.

Tres cousas nao sofrem companhia sem discordia: mandar; namorar; villăo ruim sobre cousa de seu interesse.

Năo se pode ter paciencia com quem quer que lhe falem verdade nãona usando, e com quem quer que lhe 12 façam o que não faz.

\footnotetext{
1 pernas. 2 az fehlt in ed. $1632 . \quad 3$ que me eng. 'então.

5 Abschnitt. "aindaque.

7 fazem com sua fidalguia com que lhe cavemos fidalguias de seus avós.

8 joeirado. 0 fehlt.

10 a. Diese Lesart: Und Ihr wifst ja bereits: ein schlimmer
} Bruder reicht hin, um Stoff zum Gerede über ein ganzes Kloster 7.u geben, scheint mir besser als die alte, welche Storck richtig überset $/$ t mit: Ihr wifst ja, ein schlimmer Bruder reicht hin, um einem Kloster Stoff zur Unterhaltung zu geben.

11 Diese zweite Sentenz in der hübschen Perlenschnur der hier aneinancler gereihten Weisheitssprüche lag bis jetzt nur in stark verunstalteter Form vor: Tres cousas nao soffrem (oder nan sesoffrem) sem discordia: Companhia, namorar, mandar villas ruim ctc. Die Hamburger Herausgeber verïnderten Tres zu Duas und sagten, um dem sinnlosen Satze doch irgendwclche Bedeutung cinzuschmuggeln, companhia no amar, mandar rillato ruim; eine Änderung, welche Juromenha und Braga annehmen und welche Storcks Übertragung zu Grunde liegt. Sic lautet: "Zwei Dinge gehen nicht ab ohne Zwietracht: 1) Mitgenossenschaft in der Liebe, und 2) Bevollmächtigung eines gemeinen Schurken in Sachen, die seinen Vorteil mitbetreffen". Wie die fehlerhafte Redaktion" entstand, ist leicht ersichtlich: der erste Drucker setzte aus Versehen das Wort companhia hinter sem discordia, missverstand nun den Satz und schob, ihn zu klären, ein se ein (falls dasselbe wirklich schon in ed. $1598 \mathrm{zu}$ finden ist?). Der Sinn ist: Drei Dinge dulden nicht, ohne dals Hader darausentstände, etwelche Mitgenossenschaft: 1) Liebschaften, 2) Befehle, 3) ein hartnäckiger boshafter Schuft, wenn es sich um Dinge handelt, die seinen Vorteil betreffen. Den Dichter umschwebten verschiedene Sprichwörter-Reminiscenzen, z. B. Amar não quer par; No amor näo se sofre companhia; und wohl auch Tres cousas ao homem fazem medrar: sciencil, mar e casa real und Tres cuusas destroem ao homem: muito fallar e pouco saber; muito gastar e pouco ter; muito presumir e pouco valer.

12 fehlt in allen Ausgaben. 
Desagradecimentos $a$ obras boas destruem vontades para fazel-as. Amigo' que tem mais conta co interesse que com a amizade, rézam ${ }^{2}$ d'elle. porque he dos ca nomeados.

Grande trabalho he fazer ${ }^{4}$ alegre rosto estando o coraçato tristes: panno hé que não toma nunca bem esta tinta; que a lua recebe a claridade do sol, e o rosto do coração.

Nada dá quem não dá honra no que dá: não tem que agradecer quem no que recebe a não recebe, porque bem comprado vai o que com ella se compra, nem se dá de graça o que se pede.

Muito certo est $a^{7}$, quem não tem hũa vida, $\operatorname{ter}^{8}$ muitas. Onde a rezăo se governa pela vontade, ha muito que praguejar e pouco que louvar.

Nenhũa cousa homezia os homens tanto consigo como males de que se nam guardaram, podendo.

Não ha alma ${ }^{9}$ sem corpo que tantos corpos faça sem almas como este purgatorio que chamamos: honra; onde" muitas vezes os homens cuidam que ganham, ahi perdem. ${ }^{12}$

Onde ha inveja, não ha amizade, nem a pode haver em disigual conversação.

Bem merece ${ }^{13}$ o eng:no quem cre $^{14}$ mais o que lhe dizem que o que ve ${ }^{15}$.

Agora ou se ha de viver no mundo sem verdade, ou com verdade sem mundo.

Pera ${ }^{16}$ muito pontual, perguntai-lhe de do vienef 17 e vereis que algo tiene en el cuerpo ${ }^{18}$ que le duele. ${ }^{19}$

Tomei o pulso a todos os estados da vida, e nenhum achei em perfeita saude: porque a dos clerigor. pera remedin a vejo tomar mais da vida que salvaçăo dil alma; a diss frades, indaque por baixo dos habitos, tem huns pontinkos, que que'm tudo deixa por deus, nada havia de querer do mundo; a dos casados he boa de tomar, e ruim de sostentar, e pinr de deixar; a dos solteiros barca de vidro sem leme que he bem roin navegaçăo. Ora tempe-

1. Auch dieses Sentenzenpaar ist in den bis heute überlieferten Lesarter unverständlich: Desigradecimentos de obras boas destruem a vontade para nan farellas a amigo que tem etc.

2 rezai. 3 que. I querer fazer.

s quando o coração está triste.

- Nuada se dá de grạ̧a (1632) oder nem se dá de graça o que se pede muito. schreibt.

iEstá certo (1632) oder estai certo que quem etc., wie schon ed. I65I

8 tem.

- Das Ms. schreibt fälschlich mal für alma.

10 a que chamais.

11 donde (1632). 12 cuidam que a ganham, ahi a perdem.

13 mereceu. 14 creu. überein.

15 viu. Ed. 1632 schreibt ve, stimmt also häufig mit unserem Manuscript

16 E pera. 17 donde vem.

18 Das Ms. schreibt tälschlich nel campo.

19 Abschnitt. - Storcks Vermutung, der nachfolgende Passus sei hier einzuschipben, ist also, wic bereits bemerkt ward, eine richtige. 
rai-me la essa ${ }^{1}$ gait, que, nem assi nem assi, achareis meo real ${ }^{2}$ de descanso nesta vida! o caso hes, ella nos trata como alheos, e com rezão,

Pois somente nos he dada

para ganháremos` nella

o que sabemos.

Se se gasta malgastada,

juntamente com perdel-a,

$a n \delta s^{5}$ perdemos

........... [certa]

porque mais della esperamos

e queremos,

se a vemos tam incerta

que quando a mais desejamos,

a perdemos 96

Emfim esta minha senhora(?) sendo a cousa porque mais fazemos, he a mais fraca alfaia de que nos servimos; e se queremos ver quam breve he

Ponderemos e vejamos

que ganhamos em viver

os que nascemos.

Veremos que não ganhamos

mais que ${ }^{8}$ algum bem fazer,

se 0 fazemos.

$E$ por aqui respeitando ${ }^{\circ}$

que tal o porvir será,

entesouremos;

porque ndo sabemos quando

a morte nos pedirá

que the paguemos.

1 esta.

2 Storck übersetzt: "ein wirksames Mittel für Ruhe“; falst also meo als Hauptwort, real als Eigenschaftswort auf. Wer, wie ich, täglich Klagen darüber hört, dals die portugiesischen Dienstboten nicht für fünf Reis Verstand haben (näo têm cinco reis de juizo), findet es befremdlich, dafs man meo real de descanso anders übersetzen kann als "für einen halben Kreuzer Ruhe". - Wahrscheinlich schrieb der Dichter auch nem assim nem assado - eine familiäre Redewendung, die mit dem ganzen Briefstil in Einklang steht, an welcher gewissenhafte Puristen aber vermutlich Anstofs nahmen.

3 fehlt. Die Drucke sagen ella nos trata sómente como alheios de si.

4 para que ganhemos. 5 Nos.

- Diese leider unvollständige Copla fehlt in allen Drucken.

7 Unlesbar im Ms. B Mais que.

- Auch diese Strophe stand in allen bisherigen Camoens-Ausgaben in ganz verderbter Form (diejenigen Ausgaben abgerechnet, welche sie einfach weglassen wie 1629, 1632, 1651, 1666, 1720, 1721, 1759). Die erste Zeile $E$ por isso respeitando galt für Prosa, die vierte und füfte waren so entstellt, dafs ihre Reimworte fehlten "Porque ao certo nito sabemos Quando a morte pedira". Storck suchte selbstverständlich nachzubessern: sich an die überlieferten Reimworte será entesouremos sabemos pedirá paguemos bindend, glaubte er Zeile $\mathbf{I}$ in Einklang damit bringen zu müssen, und schlug vor respcitando in respeitemos zu verwandeln. So entstand eine unschöne Strophe mit vier Reimen in emos. 
Nunca vi cousa mais pera lembrar e menos lembrada que a morte, $e^{1}$, sendo mais aborrecida que a verdade ter-se ${ }^{2}$ em menos conta que a vertude. Mas comtudo, com seu pensamento ${ }^{3}$, quando lhe vem á vontade, acarreta mil pensamentos vãos, que tudo pera com ella he lume` de palhas. E com nenhüa cousa enche tanto as medidas como com estes que vivéram na mor bonança com ella ${ }^{5}$, porque, quando the menos lembra, antam thes 6 arranca as amarras, dando.lhe ${ }^{7}$ com os corpos á costa, e se vem a måo , com as almas no inferno, que he bem ruim gasalhado; e pois $t u d 0^{\circ}$ isto temos ${ }^{10}$,

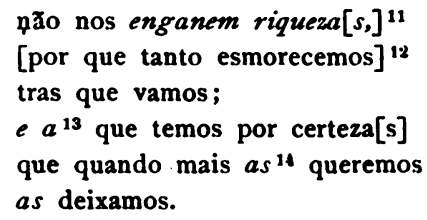

Gastamos com alcançal-as

a vida, e quando queremos

usar dellas,

nos tira a morte logral-as,

assi que a deus perdemos

e a ellas.

Porque ja ouvirieis ${ }^{15}$ dizer: "ninho feito, péga morta"..16 E concluindo aqui esta chave do jogo "7, que me dizeis ao contentamento do mundo, que toda a dura d'elle está em quanto se alcança? Porque acabado de alcaņar ${ }^{10}$, acabado de esquecer. E com rezam, porque alcançado e passado tudo hé hum. E acabado de passar, mais 19 saudade deixa do que he o contentamento que deu. Esperai, por me fazer mercé, que lhe quero dar um par de palavras ${ }^{20}$.

1 fehlt. 2 tem-se.

- Das Ms. schreibt passatempo. um lume.

- Nenhuma cousa mo enche $t$. as m. para com estes que vivem na mor bosança como ella etc. Die Stelle war in der überlieferten Lesart sichtlich entstellt, befriedigt aber auch in der des Manuscriptes nicht ganz. Der Sinn ist, dais der Tod keinem gegenüber das Mafs der Grausamkeit so ganz fullt wie gegenüber denen, welche in der allergröfsten Sorg- und Furchtlosigkeit gelebt haben. Die t'bersetzung ,Nichts entspricht denen gegenüber, welche auf heiterer See dahinfahren, so sehr meinen Erwartungen wie er" ist genau, kann aber natürlich ebensowenig. 'befriedigen wie das Original, nach dem sie gemacht ward.

The. 7 dando.

B S. S. 440 Anm. II. 9 todos.

10 Das Ms. bekandelt mit Recht $e$ pois tudo isto temos (nicht vemos), mit Unrecht näo nos enganem riquesas als Prosa.

11 engane a riquesa. 12 fehlt im Ms. $13 \mathrm{Fa}$.

$14 a$. Singular in allen Formen, während das Ms. durchgängig die Pluralformen bietet, die daher auch für riguesas und certeras angenommen werden mufsten.
16 ouvireis. 16 Sprichwort.
17 fehlt. 18 passar.
10 acabado de alcançar hé passado, e maior etc.
20 umas paluvrinhas de proposito.

Zeitschr. f. rom. Phil. VII. 
Mundo, se te conhecemos, porqué tanto desejamos teus enganos? $E$ se assi" te queremos, mui sem causa nos queixamos de teus danos.

Tu não enganas ninguem, pois, a quem te desejar, vemos que danas; se [te] querem qual te vem e $s^{2}$ querem enganar, ninguem enganas.

Veja-se os que bens ${ }^{3}$ tiveram, e os que mais em alcançarte se esmeráram 4 , que huns vivendo não viveram e outros só com deixarte descansáram. ${ }^{5}$

Nada te póde estimar quem bem quiser estimar-se 6 e conhecerte; que pois perder-te he ganhar, mais seguro he ganharse e perder-te.

1 Ed. 1651 sagt inda assi. 2 Se se.

- Vejam-se os bons que tiveram.

- Das Ms. schreibt fälschlich esmerao.

5 Hier fehlen zwei Quintillen, die in den Drucken lauten: Se esta tam clara fe Te pre claros teus enganos,

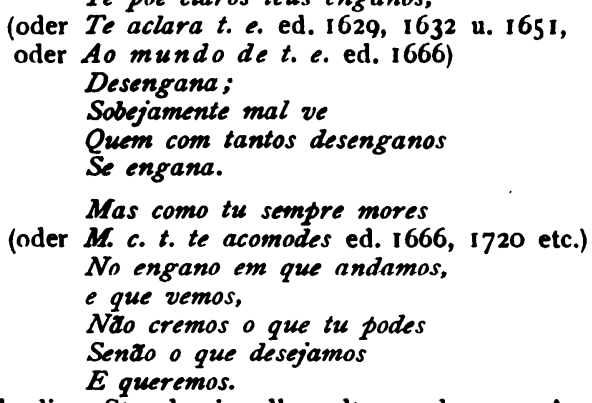

- Dafs auch diese Strophe in allen alten und neuen Ausgaben fehlerhaft überliefert war, hat Storck abermals erkannt; mit Takt und feinem Sprachsinn hat er auch hier nachgebessert und statt

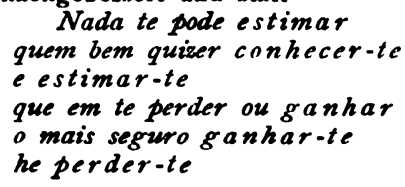


E quem em ti detremina descanso poder achar, saiba que erra; que sendo a alma divina nada a pode contentar ca na terra.'

Nascemos pera morrer, Morremos pera ter vida, em ti morrendo; o mais certo he merecer nossa ${ }^{2}$ vida conhecida ca vivendo.

Emfim, mundo, es estalagem em que pousam nossas vidas de corrida.

De ti levam de passagem ser mal ou bem ${ }^{3}$ recebidas na outra vida.

Afuera, afuera, Rodrigo!^

que se eu muito por este caminho fôr ${ }^{5}$, darei em enfadonho, aindaque me parece, que para o deixar de ser ja me não livrarão privilegios' ${ }^{6}$ de cidadão do Porto. Mas ${ }^{7}$, pois me vendo a vós, sofrei-me com meus encargos; e porque não digais que sou ereje de amor e lhe nâ sei algüas ${ }^{8}$ oraçois, vedes, vai $^{{ }^{9}}$

Di, Juan, de que murió Bras

com hum pe $i$ castelhana e outro d portugueza ${ }^{10}$. E năo vos espanteis da libré que em ${ }^{11}$ qualquer palmo d'esta materia perco o norte. $\mathrm{E}$ os soplicantes dizem assi.

die folgende Lesart angenommen:

Nada te pode estimar

quem bem quiser resguardar-te

e conhecer-te;

que em te perder ou ganhar

o mais seguro ganhar-te

he o perder-te,

welche freilich nicht, wie er annimmt, auf ed. 1720, sondern auf die ältere von 1666 zurückzuführen ist. - Die Lesart unseres Ms. scheint mir jedoch echter und besser: die unschön klingende Wiederholung derselben Ausdrücke ist eine durchaus absichtliche und schon bei Christovam Falcăo vielfachst angebrachte.

- Näo a pode descançar Nada da terra.

2 nós a. Ed. 1666 schreibt a vida mal conhecida.

3 bem ou mal. $\quad$ Cfr. Soropita IX.

s que eu se muito fôr por esto caminho.

6 de que me parece me nato livrará nem ainda privilegio etc.

$7 E$. 8 e que the nao sei oraçzes. 9 vai hüa.

10 com hum pé d portugueza e outro d castelhana. Die Lesart des Ms. ist unbedingt die echte.

11 que eu em. 


\section{Mote.}

Di, Juan, de que morió Bras?

tan niño y $\tan$ mal-logrado? -

- Gil, morió de desamado. -

\section{Volta.}

Di-me, quien le engaño'

que con Amor se engañase, pensando que el bien hallase donde $^{2}$ el mal cierto hallo? Despues que el engaño vió que hizo desengañado?

- Gil, murió de desamado.

Travou com elle pendença, , em ter razão confiado; Amor ${ }^{3}$, como he letrado, houve contra elle sentença 4 , E co' aquella diferença disse entre si o coitado;

- Gil, "morr'eu de desamado".5

Quem tem rezão tam cerrada $q^{\text {que }}{ }^{6}$ não saiba, sendo rudo e sem respeito, que sem deus he tudo nada, que nada com elle $h e^{7}$ tudo sem defeito?

E sendo isto tam ${ }^{8}$ certo, como todos confessamos, e sabemos não demos ${ }^{9}$ pelo incerto o que por tam certo damos 10 pois o vemos.

A tudo isto podeis responder que todos morremos do mal de Phaëton, porque "del dĩcho al hecho, va mui" gran trecho. F de saber as cousas a passar por ellas, ha mais differença que de se consolar a ser consolado, ou de dar conselho a tomal-o 12. Mas "assi entrou o mundo e assi ha de sahir"; muitos a reprehendél-o e poucos a emendál-o. E com isto $a c a b o^{13}$, beijando vossas ${ }^{14}$ poderosas $m$ zos hũa catrinca de vezes, cuja vida e reverenda ${ }^{15}$ pessoa Nosso Senhor accrescente por muitos annos ${ }^{16}$.

1 Di-me, Fuan, quien se engaño (ed. 1720, 1721 und 1759 lesen richtig le engaño). 2 adonde. 3 mas Amor. Ia sentenģa.

s Storcks Besserung von morreu zu morr'eu ist gut und annehmbar. Mufs man aber wirklich Gil durch fođo ersetzen? Mit Gil könnte fođo seinen Freund anrufen. ${ }^{\circ}$ quem. ${ }_{7}$ fehlt. ${ }^{8}$ isto assi tao.

9 troquemos; ed. 1632 hat demos wie das Ms.

$100 \mathrm{em}$ que tam certo estamos. 11 fehlt. 12 fehlt.

13 amaino. "14 essas. 15 reverenda.

16 fehlt. Storcks Ergänzung der Schlufsformel ist durchaus korrekt. 
No. CLIX. Z. 30 Ingrata terra, non possidebis mea ossa. Schon vor Camoens hatte Jorge Ferreira de Vasconcellos in seiner Ulysippo (1547) die Worte des Scipio Africanus benutzt. Auf S. 259 in einem abstrusen und konfusen, absichtlich „dunkel" gehaltenen Briefe sagt er: Vao que á fuza d'este desengano lanceis de todo a voar arrependimentos porque ninguem diga „bem estou", e mais quando as esperanças, afistuladas do que nao quero dizer, morrem ao desemparo tam nccessitadas que, a lhe nato vir como de por amor de deus hum "Ingrala palria nec ossa mea habebis" pera epitafio da sepullura, la vai quanto Marta fiou. ${ }^{1}$ - Z. 36-37 Auch der oft citierte Dom Francisco de Portugal flicht diese Zeile - als Nachahmer des Camoens - in einen seiner Prosabriefe ein, p. 38: A estar a senhora D. Isabel de la Cueva en otro muro asida, no hay paciencia que baste. - Z. 55 Die Phrase über die Stiere von Merceana hat Storck selbst in Bd. III 370 gedeutet. - Zu Z. 57 vgl. Jorge Ferreira de Vasconcellos, Eufrosina p. 123; Aulegr. p. 14 und $160^{*}$, wo Indien lago de honrados gescholten wird; vor allem aber den Brief des Conde de Alcoutim, in dem es heilst a Inäia, sepullura de homens nobres (s. oben). - Z. 8o se veiu cá mais humanamente heilst nicht: „kam etwas menschlicher davon", sondern „benahm sich hier etwas menschlicher". - Z. 89 Vgl. Eufr. p. 1 19. - Z. 92 Frei Pero Gonsalves s. Eufr. p. 118 und Soropita p. 58.

1 Sowohl Camoens wie Ferreira konnten diese Worte nur in humoristischer Absicht aussprechen. Ich stimme mit C. C. Branco durchaus in der Derutung des lateinischen Citates überein. Er äufsert sich darüber (L. de (Camóes, Porto 1880, p. 42) in folgender Weise: Esta carta encerra a nota melaniolica d'uma phrase de Scipião: Patria ingrata, nao terás meus wssos. Mas a comparaça, para näo ser um dislate d'orgulho, era de certu um gracejo de L. de C. Que lhe devia a patria em 1553? Elle tinha 36 annos; escrevera poemas lyricos excellentes, apenas louvados na roda dois palacianos e dos menos cultos. Ferreira e Sa de Miranda parece que nao o cunheciam. O bravo que sahira do curcere cum perdao de Gon. galu Buirge's, a quem grolpeara o cachaşo, ua o toutiço, como disseram os phy'sicoss do exame, em verdade, confrontundo-se com Scipiato Africano, ao desterrar-se nato primava em pontos de modestia. $O$ seu avantajado a indisiutizuel direito a gratida da patria, era um poema comegado apenas, ou talves auinda nao tracejado etc.

C. Micharlis de Vasconcellos. 